Portland State University

PDXScholar

$11-13-1981$

\title{
The Development and Effects of an Educational Audiovisual Presentation on Female Masturbation Upon the Attitudes and Masturbatory Behavior of College Females
}

Catherine Ann Hogan

Portland State University

Follow this and additional works at: https://pdxscholar.library.pdx.edu/open_access_etds

Part of the Health and Physical Education Commons, Psychology Commons, and the Women's Health Commons

Let us know how access to this document benefits you.

\section{Recommended Citation}

Hogan, Catherine Ann, "The Development and Effects of an Educational Audiovisual Presentation on Female Masturbation Upon the Attitudes and Masturbatory Behavior of College Females" (1981). Dissertations and Theses. Paper 3214.

https://doi.org/10.15760/etd.3205

This Thesis is brought to you for free and open access. It has been accepted for inclusion in Dissertations and Theses by an authorized administrator of PDXScholar. Please contact us if we can make this document more accessible: pdxscholar@pdx.edu. 
AN ABSTRACT OF THE THESIS OF Catherine Ann Hogan for the Master of Science in Psychology presented November 13, 1981.

Title: The Development and Effects of an Educational Audiovisual Presentation on Female Masturbation upon the Attitudes and Masturbatory Behavior of College Females.

APPROVED BY MEMBERS OF THE THESIS COMMITTEE:

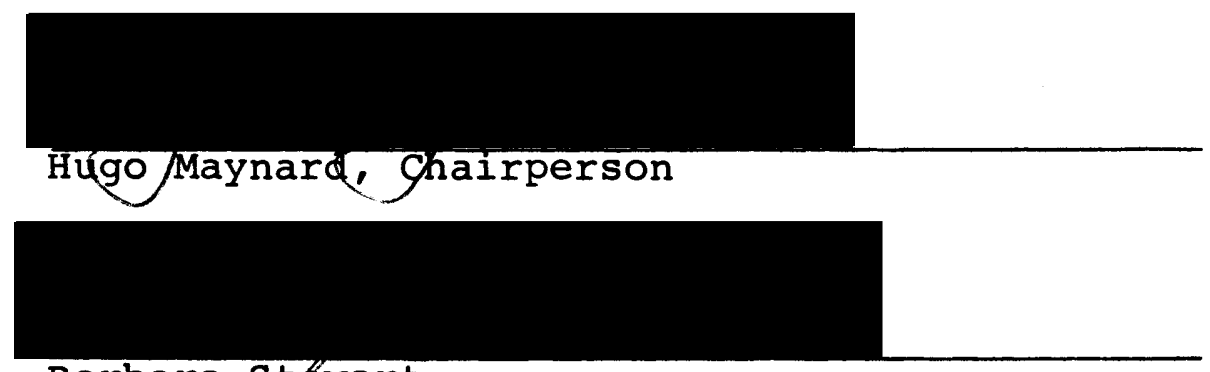

Barbara sţewart
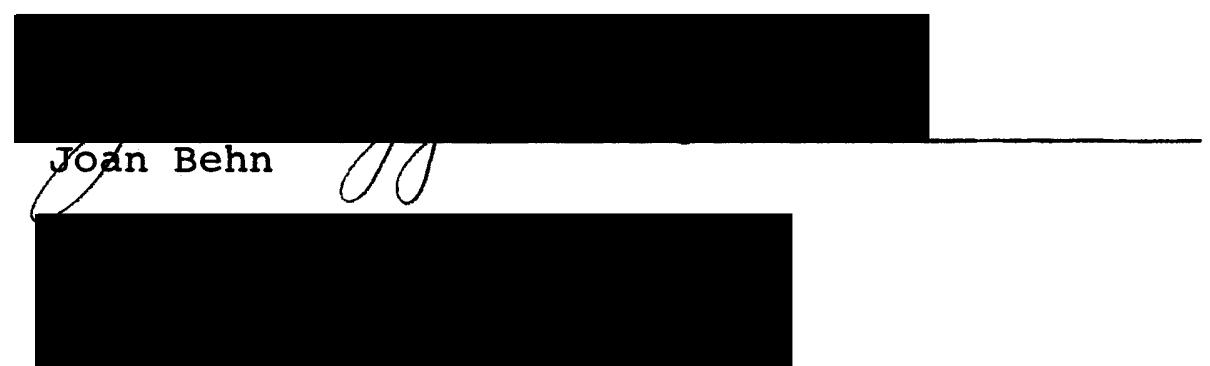

Karen Lapointe

The current study was designed: (1) to develop an educational tool on female masturbation capable of reaching a wide audience of women with accurate and complete information on female masturbation; (2) to provide initial validation for the further educational usefulness of this tool and 
(3) to assess its potential ability for improving overall sexual functioning in women by possibly altering negative attitudes toward masturbation and/or by disinhibiting masturbatory behavior.

Accordingly, the design and construction of an Educational Audiovisual Presentation on Female Masturbation, (EAPFM) is described as initially adopted from and compared to the PLISSIT model proposed for educational use with women in sexual counseling (Annon, 1971). It is further expanded on to address the informational needs of women in the general population by including additional information as was indicated by a review of the literature and sexual research in this area.

Initial validation for the further educational use of the EAPFM was measured by subjects' ratings of the EAPFM. Attitudes, masturbatory behavior and frequency rates were recorded to determine the EAPFM's potential to improve women's general sexual functioning.

Subjects for the research were 20 consenting adult female volunteers enrolled at Portland State University recruited by means of an advertisement in the school paper.

The research design provided for subjects to be matched on a measure of sexual experience then randomly assigned to one of two treatment conditions. Treatment conditions consisted of a viewing of the EAPFM or a nonviewing control. The following variables were recorded at baseline and 
at one week and four weeks after treatment: (1) attitudes toward masturbation; (2) masturbatory behavior and (3) frequency •

Results indicated that on the average, subjects tended to be sexually experienced 30 year old feminists, currently sexually active with partners, who masturbated twice weekly and exhibited positive attitudes toward masturbation.

While no significant difference was found between groups on attitudes and frequency, novel sexual behavior was noted among $30 \%$ of subjects in the experimental group. Ratings of the EAPFM indicated an encouraging response in which the majority of viewing subjects rated the EAPFM as being "very to extremely" informative; "not at all" anxiety producing and indicated that their reaction to the presentation was "very to extremely" positive.

Correlational analysis revealed a significant positive correlation between: (1) positive attitudes toward masturbation and variety of sexual experience; (2) attitudes and self rating of sexual drive; (3) frequency of masturbation and sexual experience and (4) frequency and rating of sex drive. These results were discussed as they duplicated the findings of Mosher (1973) and Abramson and Mosher (1975) in which negative attitudes, measured on the same scale, were found to be correlated with inhibited sexual behavior, and variety of sexual experience was associated with increased masturbatory frequency in college females. 
By inquiry, it was determined that only $30 \%$ of the sample were aware of the demand characteristics of the study; a majority of subjects indicated that recording their masturbatory behavior seemed to have no effect on the frequency of that behavior and a majority indicated that participating in the study had desirable effects on them personally.

The EAPFM was discussed as it relates to singular educational tools now in use. It was concluded that the informational content, specific focus and the interconnected nature of the EAPFM, subjects' reactions and the potential of the EAPFM in prompting novel masturbatory behavior was the major strength of the EAPFM and the current study.

The lack of a significant difference between groups was discussed in terms of the biased nature of the sample. The "ceiling effect" of the initially positive attitudes and the relatively high frequency of sexual behavior was noted. Also cited as a limitation was the small sample size.

It was concluded that more information was needed and that to more fully and specifically assess the educational impact and additional usefulness of the EAPFM on a more diverse population, additional research was indicated. Suggestions were offered for how this might be accomplished utilizing a larger, more cross sectional and randomized sample of women and making structural alterations in the rating system. 
THE DEVELOPMENT AND EFFECTS OF AN EDUCATIONAL AUDIOVISUAL PRESENTATION ON FEMALE MASTURBATION UPON THE ATTITUDES AND MASTURBATORY BEHAVIOR OF COLLEGE FEMALES

\section{by}

CATHERINE ANN HOGAN

A thesis submitted in partial fulfillment of the requirements for the degree of

MASTER OF SCIENCE

in

Psychology

Portland State University 
TO THE OFFICE OF GRADUATE STUDIES AND RESEARCH:

The members of the Committee approve the thesis of Catherine Ann Hogan presented November 13, 1981.

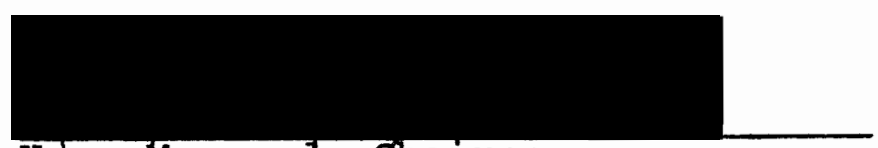

Hugo Maynarde Chairperson

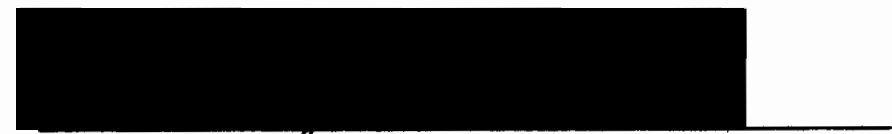

Barbara Stewart

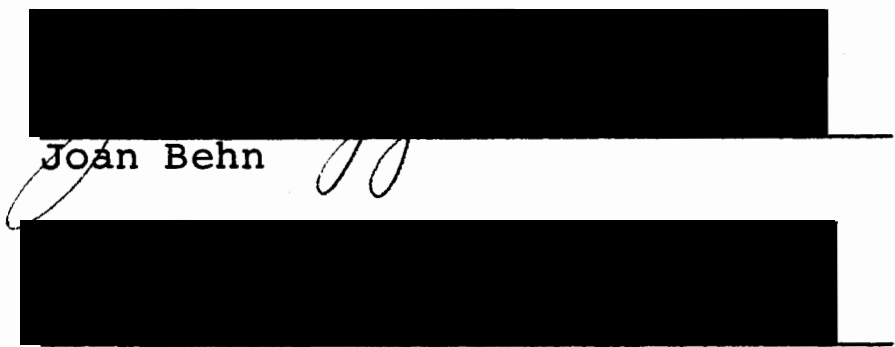

Karen Lapointe

APPROVED :

David F. Wrench, Head, Department of Psychology

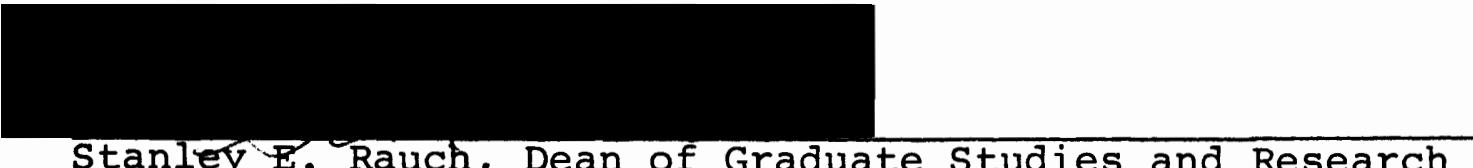

Stanley $\mathrm{E}$. Rauch, Dean of Graduate Studies and Research 
TABLE OF CONTENTS

PAGE

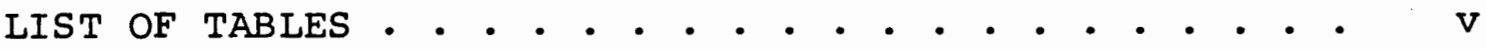

INTRODUCTION . . . . . . . . . . . . . . . . I

PLISSIT MODEL AND OBSERVATIONAL LEARNING

TECHNIQUES ADOPTED . . . . . . . . . . . . . . . 9

METHOD . . . . . . . . . . . . . . . . . 17

Subjects . . . . . . . . . . . . . 17

Description of the Educational Tool:

"Educational Audiovisual Presentation

On Female Masturbation", (EAPFM).......

Part I: Basic Information . . . . . . 17

Part II: Permission ....... 18

Part III: Specific Suggestion . . . . . . 21

Questionnaires... . . . . . . . 22

PROCEDURE . . . . . . . . . . . . . . . 27

RESULTS . . . . . . . . . . . . . 32

Demographic and Sexual Characteristics

of Subject Sample ............ . 32

Attitudes Toward Masturbation . . . . . . 35

Significant Correlates . . . . . . . 35

Post Treatment Measurement: Differences 36

within and between Groups, Weeks $1 \& 4$. . 36

Frequency of Masturbation . . . . . . . 37

Significant Correlates . . . . . . . 37

Post Treatment Measurement: Differences

within and between Groups, 'Neeks $1 \& 4$. . 40 
TABLE OF CONTENTS cont'd

PAGE

Novel Masturbatory Behavior Demonstrated . . . 40

Subject Ratings of the EAPFM . . . . . . . 41

OBSERVATIONS................... . . . 43

DISCUSSION .................. . . . 49

CONCLUSIONS AND RECCOMENDATIONS . . . . . . . . 54

BIBLIOGRAPHY . . . . . . . . . . . . . . . 56

APPENDICES .................... 66 
LIST OF TABLES

TABLE

PAGE

1. EXPERIMENTAL DESIGN AND PROCEDURAL FLOW CHART • . . . . . . . . . . • . . . 29

2. DEMOGRAPHIC CHARACTERISTICS OF FEMALE

SUBJECT SAMPLE • • • • • • • • • • • • 33

3. SEXUAL CHARACTERISTICS OF FEMALE

SUBJECT SAMPLE • • . • • • • • • • • • 34

4. ATTITUDES TOWARD MASTURBATION AND WEEKLY

FREQUENCY OF MASTURBATION OVER TIME

BY CONDITION • . . . . . . • • . . 38

5. INTERCORRELATIONS OF ATTITUDES TOWARD AND

FREQUENCY OF MASTURBATION WITH

SELECTED VARIABLES AS INDICATED • • • • . 39

6. OPEN ENDED RESPONSES OF SUBJECTS IDENTIFYING

EFFECTS OF EAPFM AND OVERALL

PARTICIPATION IN RESEARCH . . . . . . . 46 


\section{INTRODUCTION}

It is known that masturbation when compared to any other form of sexual stimulation including intercourse, is the type of sexual stimulation most likely to produce an orgasm in females (Kinsey, Pomeroy, Martin \& Gebhard, 1953).

It has also been demonstrated that masturbation produces the most intense orgasms in females (Masters \& Johnson, 1966).

It is also known that intense orgasms increase female sexual responsivity and potential for future orgasms (Kegel, 1952; Sherfey, 1966; Bardwich, 1971, 1978), and that given adequate stimulation females are capable of multiple orgasms in any given sexual encounter (Masters \& Johnson, 1966).

Further, sexual research has indicated that teaching women how to masturbate has resulted in increasing their ability to be orgasmic (LoPiccolo \& Lobitz, 1972; Annon, 1973) and in successfully generalizing this increased orgasmic responsiveness to heterosexual coitus and interaction with a partner (Wallace \& Barbach, 1974).

This information about female masturbation has obvious functional, sexual and psychophysiological benefits to women and their partners. In a country where some $10-12 \%$ of American women are estimated to be completely nonorgasmic (Kaplan, 1974; Hite, 1977), this valuable information about female self stimulation is neither readily accessible to women nor is it directly, comprehensively and supportively presented through the predominant educational channels avail- 
able to a wide cross section of female audiences.

One large audience of women is found among those vho attend high school and college sex education courses. While recently published human sexuality texts aimed at this population are increasingly providing an enhanced discussion of self stimulation as one of a myriad of sexual behaviors, the focus, reflective of the historical taboo on this subject, is typically on eliminating myths and dispelling unwarranted fears about masturbation; on presenting historical and prevailing attitudes; cross cultural comparisons and on citing statistical reports and other ethnographic concerns (Katchadourian and Lunde, 1972; McCarthy, Ryan \& Johnson, 1975; Hunt, 1974; Mosher, 1979; McCary \& Copeland, 1976).

As a rule, the available research data on female masturbation referenced on page $I$ is absent from this literature. In those instances where some portion of this significant body of knowledge is briefly noted, inferences are not drawn to outline the implications of the data for increasing womens sexual functioning, nor is this data discussed permissively in light of its importance. Masturbation is in no way supportively presented nor advocated as a healthy sexual behavior for women.

Even more fundamentally, it has been bourne out in sexual therapy and from other sources that, due in large part to a lack of or to inadequate information, women are frequently not sufficiently aware enough of their own anatom- 
ical genital structuring (LoPiccolo \& Lobitz, 1972; Annon, 1974; Barbach, 1974, 1975; Hite, 1976) and/or are unaware of the role of the clitoris in precipitating an orgasmic response (Sherfey, 1966; Masters \& Johnson, 1966; Hite, 1976), equally absent from sex education literature are efforts to suggest to or to instruct women how self stimulation might be accomplished.

In fact, it has been asserted that female masturbation has been virtually ignored in the educational literature and that much more emphasis has been placed on male patterns of masturbation than female patterns of masturbation in the data made available (Arafat \& Cotton, 1974). Further, it has been charged that the literature has presented a "phallocentric" view in which the importance of female orgasm has been underestimated (Sherfey, 1966; Barbach, 1975; Hite, 1976) and additionally that clinical observations and theoretical formulations have been inappropriately and inadequately generalized with the male as the focal point (Clower, 1975).

The lack of knowledge about female masturbation has not been without it's psychological, attitudinal, emotional and behavioral impact on women. In addition to a poor working knowledge of genital anatomy and functioning, the contribution of inadequate knowledge in precipitating possible sexual dysfunction in females can further be appreciated when the relationship between poor education and limited knowledge about masturbation, negative attitudes toward masturbation 
and inhibited sexual behavior, masturbatory frequency and rate of orgasmic response is explored.

It has been demonstrated that lowered education, decreased information about and exposure to female r.asturbation has been correlated vith increased negative attitudes toward female masturbation in college women (Miller \& Lief, 1976).

Further, it has been demonstrated that negative attitudes toward masturbation are highly correlated with guilt in college women (Abramson \& Mosher, 1975; Greenberg \& Archambault, 1973). Other studies, utilizing a random sampling of women have indicated that the majority of the female sample similarly reported negative attitudes toward masturbation and associated guilt (Schaefer, 1973; Hite, 1976).

In turn, it has been demonstrated that negative attitudes and guilt over self stimulation in females is related to less varied sexual experience and with less masturbatory experience (Abramson \& Mosher, 1975), and has additionally been shown to be associated with inhibited masturbatory frequency (Abramson \& Mosher, 1975; Schuetz, 1978) as well as inhibited orgasmic response in both masturbation and intercourse (Bentler \& Peeler, 1979).

From these data it has been concluded that negative attitudes toward masturbation as well as sex guilt serve to inhibit both sexual experience and orgasmic success in women (Abramson \& Mosher, 1975). 
Correspondingly, clinical research with sexually dysfunctional females indicates that: (1) negative attitudes and guilt over masturbation are frequently demonstrated by women who are nonorgasmic or are otherwise sexually dysfunctional, and (2) has been named as the first significant barrier to be overcome in the treatment of sexual dysfunction in order to promote effective sexual functioning in women (Robinson, 1974).

It has been in the area of sexual treatment that the implications of this data have been most directly applied and educational efforts have been concentrated. Hence, efforts to educate women about the role masturbation can play in increasing their own sexual responsiveness have been primarily directed to the select clinical population of sexually dysfunctional females.

As an adjunct to continuing sexual research and the concurrent development of a variety of educational models developed in the context and confines of sexual therapy, subsequent efforts made to educate women and to expand the female audience increasingly resulted in popularized literature which then became available to a similarly select reading audience of women. Here, while the focus was on "how-to" and self help rather than clinic based treatment, the emphasis nevertheless remained on employing sexual self stimulation as a means of treatment for overcoming orgasmic difficulties.

In a country where some $9,129,616$ to $10,955,540$ women 
in the United States ${ }^{1}$ are estimated to be nonorgasmici in a country where increasing numbers of women are seeking treatment for sexual dysfunction (Robinson, 1974); and in a country where this same select group of highly motivated, economically advantaged and predominantly middle to upper middle class women (Robinson, 1974), along with their motivated, literate and self-treating contemporaries are perhaps the tip of the iceberg among those in the general female population who may be equally sexually dysfunctional or otherwise dissatisfied with their sexual responsiveness, more emphasis is placed on the treatment of sexual dysfunction than on increasing broad based educational efforts to share this knowledge and at increasing educational efforts aimed at its prevention.

A valuable contribution which seems necessary here is the development of an educational tool through which: (1) the currently available body of research data on female masturbation could be completely and uniformly detailed in a succinct fashion; (2) include the informative detailing of women's sexual anatomy and offer instructions in masturbatory techniques; (3) permissively discuss this information within the context of its benefits in increasing female sexual functioning; (4) female masturbation would be presented as a valuable sexual behavior in its own right with the potential for increasing one's sexual self awareness and sexual communication

${ }^{1}$ Computed from the 1980 Census of the Population: United States. 
skills rather than restrictively viewed as a sexual behavior which primarily had therapeutic value in ameliorating orgasmic difficulties; (5) negative attitudes toward female masturbation and dysfunctional behaviors could possibly be reduced or eliminated; and (6) a larger audience of women could be reached through its flexibility to be used in a variety of settings.

Four steps were necessary to develop an educational model for such a flexible, broad-based presentation on the subject of female masturbation.

The first step was to undertake a review of the literature. An understanding of three areas seemed essential. Initially, it was necessary to review the mores and attitudes of Western society in which women are a subculture from a historical perspective in order to appreciate the frequently deep seated nature of sexual attitudes and behaviors regarding female masturbation.

Secondarily, in order to establish a model for educating women about a matter as intimate and sensitive as their own sexual self stimulation that would concurrently maximize sensitivity to these issues and audience receptivity to the educational material, it was necessary to explore women's current attitudes toward and feelings about masturbating. Finally, in order to identify appropriate and effective educational models; to establish what has and hasn't empirically been proven effective in educating women about masturbation; determine how women can best learn about an emot- 
ionally and socially charged issue; and to identify possible ways in which this model could be implemented, a summary of the literature on observational learning techniques was also reviewed. Also reviewed were intervention strategies, techniques and learning models developed and used for sexual education in the context of sexual therapy -- specifically those in use in masturbation training and the education of sexually dysfunctional women.

Highlights of the review relative to the purposes of this research are included here in the presentation of the educational model.

After the review of the literature was completed, the second step was to identify and select a conceptual framework and educational model which best suited the current purposes.

A third step was to similarly identify and select effective learning techniques and intervention strategies that would work well in delivering the model.

Having completed this, the fourth step was to decide on a workable format and medium of communication. The fifth step was to design and further develop the instructional tool itself, deciding how to efficiently translate and flesh out the educational strategies into effective communication with a clear message.

The sixth and final step was to design a study which would measure and attempt to validate the effectiveness of this educational tool for use with a nonclinically based population of women. 
PLISSIT MODEL AND OBSERVATIONAL LEARNING TECHNIQUES ADOPTED

An educational model meeting the issues raised in the review of the literature and in keeping with the goals of this research was the PIISSIT model proposed by Annon (1974) in which a conceptual scheme for the use of vicarious learning in sex therapy was proposed. PLISSIT is an acronym for the suggested methods of handling sexual concerns, and provides for four levels of approach. The four levels are: Permission, Limited Information, specific suggestions and Intensive Therapy.

In this model Annon identified appropriate behaviorally based intervention strategies to be used with specific "types" of sexual concerns typically raised in the context of the treatment of sexually dysfunctional women. Making clear the broad spectrum approach of his model, Annon indicated that these approaches, which he referred to as brief intervention strategies, could flexibly be used singularly or in combination, depending on the needs of the population and lent themselves well to application in a variety of settings.

Three of the four intervention strategies Annon proposed were relevant to the purposes here. These three strategies, were empirically proven to be clinically successful (Annon, 1971) in effectively reshaping and/or extinguishing specific types of sexually dysfunctional attitudes and behaviors and in effectively answering and calming specific types of sexual questions, concerns and fears. It is with their educational value as teaching tools and their direct application and 
generalization to the sexual education of a wider audience of women that the current design is concerned.

Permission

Giving permission was defined as the offering of permission from an authoritative, respected source to the seeker of information to engage in a given sexual behavior. The goal here is to have the woman with the concern learn to be permissive with herself and, in turn, to accept the validity of the sexual behavior and her respective right to engage in it.

In addition to offering and modeling a permissive attitude, a secondary goal is reassuring the woman that the given sexual behavior is "normal" and "okay" and that the woman as an individual is also "normal" and "okay". It was Annon's experience that, more often than not, women requiring this level of intervention were not as bothered by the specific behavior as by the cultural attitudes toward the behavior or the thought that significant others might view it as inappropriate or wrong.

This strategy was indicated as being most successful with women who felt "perverted", "deviant" or somehow "abnormal" because they felt a certain sexual desire, engaged in a certain sexual behavior or did it differently or more often than someone else.

This strategy would be used in the current study by 
offering women who commonly felt that they were "perverted", "deviant" or somehow "abnormal" if they masturbated, reassurance that this was not the case; that masturbation was normal, that other women felt "okay" about it, and that it was a permissible sexual behavior in the mind of the authoritative role model.

\section{Limited Information}

offering limited information was defined as the giving of specific, factual information by an authoritative, respected source to the seeker of information. The goal here is to supply accurate information about a specific sexual behavior and to replace fiction with fact.

Annon discovered that this strategy proved to be most successful in changing sexual attitudes and behaviors when the basis for the maladaptive patterns were essentially related to inadequate, culturally biased, erroneous, otherwise incomplete or nonfactual information about the sexual behavior or sexual functioning, the universality or frequency of it's occurrence. Concurrently, Annon indicated that this strategy proved to be an excellent method for effectively dispelling longstanding sexual myths, taboos and unnecessary fears.

This strategy was noted as being most successful with women who simply may not have known about a given sexual behavior, how common a practice it was, how frequently others engaged in it relative to her own frequency or who feared illogical consequences accruing to her for engaging in the 
sexual behavior in question. For the purposes of this study, this strategy would be appropriate for women who did not know what masturbation was; whether or not women even did it, or how frequently they did it, or who harbored antiquated beliefs that masturbation could cause warts, would weaken the masturbator, drain her energy and libido, incapacitate or otherwise interfere with her ability to be sexually responsive with a partner, or who felt it meant that she was homosexual, personality disordered, socially inadequate or otherwise neurotically impaired.

For the purposes of this study, this strategy would apply by providing a definition of female masturbation, and facts regarding how commonly or universally it is practiced among women, how frequently it is engaged in and by providing accurate, complete information about female masturbation including studies of personality correlates, which would debunk historical myths and disprove the concept that women who masturbate are neurotic or otherwise not well adjusted human beings.

\section{Specific Suggestion}

Unlike permission and limited information giving which do not propose that an information seeker take any active steps to engage in a particular behavior to change unless she chooses, this particular strategy is defined as the giving of specific suggestions on the part of an authoritative or other- 
wise respected source, for some action to be taken on the part of the female to facilitate change or the gaining of additional knowledge or experience for establishing more positive attitudes or behaviors enabling the individual to meet personal sexual goals.

The goal here is to facilitate change toward more individually productive attitudes or behaviors with the assistance of a behaviorally concrete action plan. Depending on the specific sexual goal and the other goals of the individual, these suggestions may take several forms.

Frequently, a secondary goal here is concurrently to reduce the female's personal anxiety about engaging in the action suggested, to desensitize her perception of the action plan itself as a new or changed behavior pattern she may in some way fear, and to offer support for engaging in the action suggested.

This strategy proved to be most successful in working with females whose specific sexual concerns could not sufficiently be met by the first two strategies individually or in combination. Annon indicated that this strategy was very successful with women who simply did not have sufficient information to know how her body worked, how a specific sexual behavior was engaged in, or who feared attempting a sexual behavior that had never before been attempted or had proven satisfactory.

This strategy would apply to the current study by offer- 
ing women who were unaware of the structure of their own sexual anatomy, were unaware of the role of the clitoris in precipitating an orgasmic response, and/or were simply unaware of how a woman could sexually stimulate herself, with the information necessary to get to know the anatomical structure of her own genitals; to become more familiar with the basic physiology of orgasm and with the instructions for how a woman can masturbate.

After an overview of the literature on operant conditioning and behavior modification, social learning theory and observational learning (Bandura, 1969, 1971; Wolpe, 1969; Mikulas, 1972; Franks, 1973; Skinner, 1976) a review of some of the clinical applications of these learning techniques (Franks, 1964; Neuringer, 1970; Rachman, 1972) and a review of their application in promoting the learning of new sexual behaviors and attitudes in sexual therapy as they related to sexually dysfunctional females (Annon, 1971, 1974; Wincze, 1971; LoPiccolo \& Lobitz, 1972; Barbach, 1974; Kohlenberg, 1974; Robinson, 1974; McMullen, 1977; McMullen \& Rosen, 1979), observational learning techniques seemed best suited for the current purposes and were accordingly selected for use and incorporation into the current educational model on female masturbation.

For the purposes of the current research, specific observational techniques applied herein included the use of: (1) vicarious learning through individualized symbolic role 
modeling; (2) peer role modeling; (3) social facilitation; (4) direct and covert reinforcement; (5) identification; (6) suggested imitation and (7) directed sexual behavior modeling utilizing shaping, hierarchial ordering, successive approximation and systematic desensitization techniques (Wolpe, 1958, 1969; Lazarus, 1960, 1968; Feingold, 1966; Kraft, 1969; Rachman, 1967, 1970; Ince, 1973).

After a review of the literature noting the recent increase in the logical application of the principles of observational learning to the use of audiovisual aids in sexual therapy (Wincze, 1971; Wincze and Caird, 1973; More, 1973, Renick, 1973; Robinson, 1974; Lehman, 1974) and research conducted to provide empirical data to support the alleged disinhibiting effects of these visual aids (Robinson, 1974; Heiby and Becker, 1980), an audiovisual format was selected as the most efficient, appropriate and convenient communication medium to utilize for the current purposes.

Purpose of the Study

The current study was designed to develop an educational tool on female masturbation capable of reaching a wide audience of women with accurate and complete information on female masturbation; to provide initial validation for the further educational usefulness of this tool and to assess it's potential ability to alter negative attitudes toward masturbation and/or to improve overall sexual functioning in women. 
In order to accomplish this, female viewers were asked to assess the educational presentation on female masturbation, and conjointly data was gathered which would reflect evidence of novel masturbatory behavior or increased masturbatory behavior and changes evidenced in female subjects' attitudes toward masturbation occuring directly as a function of viewing the presentation.

While subjects' reactions to the EAPFM and its potential to precipitate change was unknown, it was hypothesized in this study that, in comparison to untreated control subjects, women in the experimental group exposed to the EAPFM would likely: (1) demonstrate a measurable increase in positive attitudes toward masturbation; (2) demonstrate a measureable increase in weekly masturbatory frequency; and/or would (3) demonstrate novel masturbatory behavior. 


\section{METHOD}

Subjects

Subjects for the research were volunteer adult female college students, aged 18 or over who were enrolled at Portland State University and gave their consent to participate in the current study.

Description of the educational tool: "Educational Audiovisual Presentation on Female Masturbation", (EAPFM)

In keeping with the three part focus of the educational model selected, and the further goals of minimizing viewer fatique and maximizing subsequent use, it was determined that a three part series of videotaped or filmed presentation, each individually focused on providing basic information, permission and specific suggestions would be employed.

In keeping with the concept of gradual desensitization, it was decided to order the presentation of the educational material sequentially, from that which was determined to be least potentially anxiety producing to that which was determined to be most potentially anxiety producing.

The following is a description of each of the three component parts of the EAPFM in the order in which they occurred. Part I: Basic Information

This thirty minute, black and white, $1 / 2$ inch reel to reel videotape, designed and produced by the author, entitled simply, "Masturbation Lecture", depicts a woman known and identified as a female sexuality instructor, standing behind a podium in an academic classroom setting who offers informa- 
tion in the form of a lecture on the subject of female masturbation. The lecture, delivered in a very matter-of-fact manner, addressing the issues raised in the review of the literature and in keeping with the goals of the EAPFM: (1). offers a brief highlighting of the historical development of the taboo against masturbation in Western society; presents commonly held myths, fallacies and misconceptions about female masturbation; (3) recounts research findings documenting womens' negative attitudes toward and conflictful feelings about female masturbation; (4) examines these attitudes and feelings in light of information on sex-role conditioning and cultural norms for sexual conduct; (5) notes research exploring the relationship of these psychosexual conflicts on inhibited sexual functioning in women, and (6) offers facts from the body of scientific knowledge currently available on female masturbation, including: (a) the frequency of masturbation among women in the United States; (b) the sexual physiology of masturbation and orgasm and (c) the orgastic and other benefits of this sexual behavior, identified by sexual researchers, educators and therapists as being valuable for sexual growth.

\section{Part II: Permission}

As the first part was focused on information, this portion of the EAPFM is designed primarily to offer permission to the female viewer. By design it seeks to accomplish this through the use of information sharing, self-disclosure, peer 
role modeling, peer support, identification and the suggested imitation and social facilitation of these attitudes and sexual behaviors for the viewer.

This sixty minute, black and white, reel to reel videotape, entitled "Speaking out on Masturbation: Five women discuss the role masturbation has played in their own sexual growth and development" was designed and produced by the author.

Here, the same authoritative female role model is employed, similarly identified as a female sexuality instructor. The videotape consists of this female instructor interviewing a series of five women sequentially, in a one-to-one format, within a relaxed residential setting, about their respective feelings about, attitudes toward and individual masturbatory behavior, past and present.

By design, questions and answers and specific information was offered female viewers with regard to: (1) how these women learned about or discovered masturbation; (2) what they had been taught and had learned about masturbation as a child, an adolescent and an adult; (3) what their attitudes were and how they felt about masturbation now; (4) in what ways their attitudes and feelings had changed over time; (5) what had changed these beliefs and emotions; (6) the age at which they first masturbated and how they felt about it; (7) how and in what ways they continued to masturbate over time; (8) how frequently they masturbated currently; (9) how they mastur- 
bated and what techniques they preferred to use; (10) how masturbation was currently a part of their current sexual expression; (11) how their partner(s) felt about this; (12) how they felt about their partner's perceptions; (13) when they first masturbated to orgasm and how that felt; (14) how orgasms through self stimulation compared in sensation, etc. with orgasms induced by intercourse or other sexual stimulation; (15) what they liked about sexual self stimulation and why it was/is important to them; (16) what role masturbation played in their own personal sexual growth and development; and (17) what advice they might offer to female viewers who perhaps do not have positive feelings or attitudes about female masturbation.

All subjects who participated in this videotape: (1) agreed to participate in the videotaping and to state their personal, sexual views in front of a camera; (2) currently masturbated; (3) viewed masturbation as a normal sexual activity for females and a natural part of the expression of female sexuality; (4) felt "good" about their own masturbation and saw it as an integral part of the continuing expression of their own sexuality as women; and (5) identified their sexual orientation as heterosexual.

While all of the female participants in this videotape happened to be of the same race, Caucasian, they were choicefully dissimiliar in: (1) age (23 to 45 years of age); (2) sexual experience; (3) orgasmic experience; (4) current and/ 
or preferred level of sexual activity; (5) marital status;

(6) availability of a sexual partner(s) or intimate(s); (7) life style; (8) values; (9) socioeconomic status and (10) income level.

\section{Part III: Specific Suggestion}

This portion of the EAPFM is primarily designed to offer specific suggestions to the female viewer about female masturbation. It does this by offering verbal suggestions that are concurrently behaviorally modeled or otherwise illustrated.

Chosen for this portion of the EAPFM is a $281 / 2$ rninute color film entitled, "Reaching Orgasm", produced at the University of California, San Francisco (Barbach and Wallace, $1974)$.

The film provides the female viewer with instruction in female genital anatomy by labeling the appropriate body parts and subsequently locating them on a live mode. Additionally, the film offers instructions in how to masturbate by modeling this sexual behavior directly. In keeping with the principles of systematic desensitization, this directed sexual behavior is modeled hierarchially, using graduated behavior in a series of incremental steps successively approximating the culmination of masturbation and the arrival at orgasm.

specifically, the film depicts a live female model:

gradually disrobing; (2) touching and massaging her whole body; (3) examining and exploring her genitals manually; gradually beginning to manually stroke her clitoris, until 
(5) she reaches the point of sexual arousal and then (6) continues manual sexual self stimulation to the point of orgasm.

Other than the observational learning which occurs as a function of the direct modeling, the film additionally provides instruction in how to masturbate, as well as direct reinforcement, covert reinforcement and suggested imitation as a means of learning through the use of a voiced over verbal message offered by a female in a soft, well modulated voice, which indicates concurrently with the shaped behavioral demonstration, what the model is doing at each of the steps indicates how pleasurable the activity the model is engaging in is; how you as a viewer could imagine engaging in it yourself and could feel similiar sensations.

The film further reinforces the concept that masturbation is a valuable, beneficial sexual behavior for women by indicating that it can lead to increased sexual and anatomical self awareness, increased orgasmic functioning and increased communication and sexual interaction with a partner.

Questionnaires

A total of eight separate questionnaires were utilized in the current research. In order of completion they were the Informed Consent Form; the Demographic Questionnaire; the Sexual Information Sheet; the Sexual Variety Inventory; the Attitudes Toward Masturbation Questionnaire; the Weekly Sexual Self Report; the Viewer Rating sheet and the Follow Up Ques- 
tionnaire. A copy of each instrument is contained in the Appendix section. A description of each measure follows. Informed Consent Form

The Informed Consent Form was drafted by the author, along the lines of one designed for sexual research by Mosher (1971), after consultation with Portland attorney, Don H. Marmaduke, regarding necessary and proper content. Containing a note about the nature of the research and a descriptive text, it requires the signature of the subject to statements that the signer/subject is at least 18 years of age and is cognizant of the fact that as a research subject she may be asked to view sexually explicit material.

Demographic Questionnaire

The Demographic Questionnaire, developed by the author in a quick, check-off format is a fairly routine measure which requests the age, marital status, educational level, ethnic background, income level and preferred faith of the subjects. Additionally, this instrument requests informants to self rate their religious devoutness along a four point continuum from "very" to "not" devout, and utilizing a referenced definition, to similarly rate themselves as being in agreement with the statement that they consider themselves as "feminists", "not feminists" or are "undecided" about how this definition fits their values and beliefs.

The questionnaire yields descriptive information on the subject sample relative to these variables. 


\section{Sexual Information Sheet}

The Sexual Information Sheet was developed by the author. It requests that the informant respond to six bipolar items requesting a "yes"/"no" agreement or disagreement to statements about self perceived satisfaction with sexual responsiveness, the experiencing of sexual tension, etc. Additionally, it asks subjects to identify sexual orientation and preference; to rate their sex drive along a graduated five point scale from "no drive" to "high drive" and to respond in a "yes/no/don't know/never attempted" format to a question asking whether or not they have ever experienced orgasm.

This questionnaire yields descriptive information on the subject sample relative to these nine variables. The focus here is on assessing subjects current sexual situation and their current level of comfort and satisfaction with their own sexuality.

\section{Sexual Variety Inventory}

The Sexual Variety Inventory, as developed by the author was expanded from the list of seventeen heterosexual behaviors identified by LoPiccolo and steger (1974) to twenty six sexual behaviors in which the sex of the referent partner could either be male or female.

The inventory, appearing with a bipolar "yes/no" response set, asks subjects whether or not they have ever engaged in the sexual behavior identified. This yields a quantative total of sexual behaviors engaged in, and as such, is 
a quantifiable way of measuring a given subjects' range of sexual behavior using a common referent.

Attitudes Toward Masturbation Questionnaire

The Attitudes Toward Masturbation Questionnaire, developed by Abramson and Mosher (1975) is a thirty item Likert type scale which requests disagreement or agreement across a five point scale to such items as: "Masturbation is an escape mechanism which prevents a person from developing a mature sex outlook"; "Masturbation can provide harmless relief from sexual tensions".

Results of the factor analysis of the items and $t$ tests for sex differences on each item can be found in the publication of this study ${ }^{1}$. Item analysis indicated that all but the first item were correlated significantly with the total score and that twenty four of the thirty items correlated beyond the .001 level with the total score.

The split-half reliability coefficient corrected by the Spearman-Brown phrophecy formula was .75 and attested to the psychometric soundness of this measure. The correlations between this measure and the average estimated frequency of masturbation per month in both males and females suggested the strongest evidence thus far for the instruments validity.

Weekly Sexual self Report

The Weekly Sexual Self Report as developed by the author,

${ }^{1}$ Paul R. Abramson and Donald L. Mosher, The Development of a Measure of Negative Attitudes Toward Masturbation. Journal of Consulting and Clinical Psychology, 136-146. 
is a listing of eight sexual behaviors, the first five of which were directly modeled in the auiovisual presentation, listed in graduated order. This form asks the subject to fill in the number of times daily within the period of one week, that the particular sexual behavior was engaged in. Viewer Rating sheet

The Viewer Rating sheet as developed by the author, asks that subjects rate each of the three segments of the EAPFM using a five point scale, from "extremely" to "not at all" in rating each part of the EAPFM on how informative it was; how anxiety producing it was and whether or not subjects had a positive reaction to the EAPFM overall. Additionally, the rating sheet solicited subjects' subjective reactions.

\section{Follow Up Questionnaire}

The Follow Up Questionnaire, as developed by the author, is a six item questionnaire, utilizing a bipolar yes/no format. The focus of this questionnaire was to: (1) determine to what degree subjects might have been aware of the design of the study or of what it was designed to measure; (2) to determine to what degree recording sexual behavior might mave influenced the frequency of sexual behavior: and (3) to determine whether or not engaging in the study had any kind of unanticipated negative impact on the subject, subject's behavior, or attitudes or on any other individual in the subjects life who might, however vicariously been affected by her participation in the research. 


\section{PROCEDURE}

Female subjects were recruited by means of an advertisement in the University newspaper and through announcements in high enrollment University classes. A copy of the advertisement/announcement used can be found in the Appendix. At specific times, in keeping with the announcement, an orientation and recruitment meeting was held, providing pottential subjects with more information.

This recruitment meeting established that as participants, subjects would be requested to: (1) record sexual behavior for a specific time period; (2) view a sexually explicit audiovisual presentation; (3) return to the University for two subsequent meetings, held one week and five weeks from that time, and (4) would be asked to complete and return two sets of questionnaires by mail. Further, the importance of commitment and follow through in the study was stressed. The issue of confidentiality was addressed and potential subjects were assured of the anonymity of their responses. Subjects indicating an interest in participating in the study were asked to remain after a scheduled break.

In this initial meeting, basic demographic information was requested as was information on which subjects would be matched. Folios were distributed to each subject containing an Informed Consent Form, a Demographic Questionnaire, a Personal Sexual Information Sheet, the Sexual Variety Inventory, an index card, post cards and envelopes. Appropriate 
instructions were given and subjects were requested to sign the form, complete the questionnaires and to self-address the material to be used for future mailing purposes. Subjects were told that they would be notified by mail of one of two previously identified times to return to the University on the date of the second meeting.

Following the first meeting and the tabulation of the data collected at that time, subjects were matched on variety of sexual experience as measured by the sexual Variety Inventory score, a variable shown to be correlated with positive attitudes toward masturbation. Subjects $(N=20)$ were then randomly assigned to one to two treatment groups: experimental or control, and were accordingly informed by mail of the time of their return meeting (See Table 1 ).

At the second meeting, at which point subjects had been divided into one of two separately convened groups $(N=10)$, folios were again distributed containing an Attitude Toward Masturbation Questionnaire and a Weekly Sexual Self Report Form. Instructions were offered for the accurate completion of these forms and were filled out by the subjects. Baseline data on attitudes, masturbatory behavior and frequency was thereby gathered in both groups. Following this portion of the meeting, experimental subjects viewed the EAPFM and completed the Viewer Rating Sheet; control subjects did not view the EAPFM.

As a follow-up to the second meeting, all subjects 


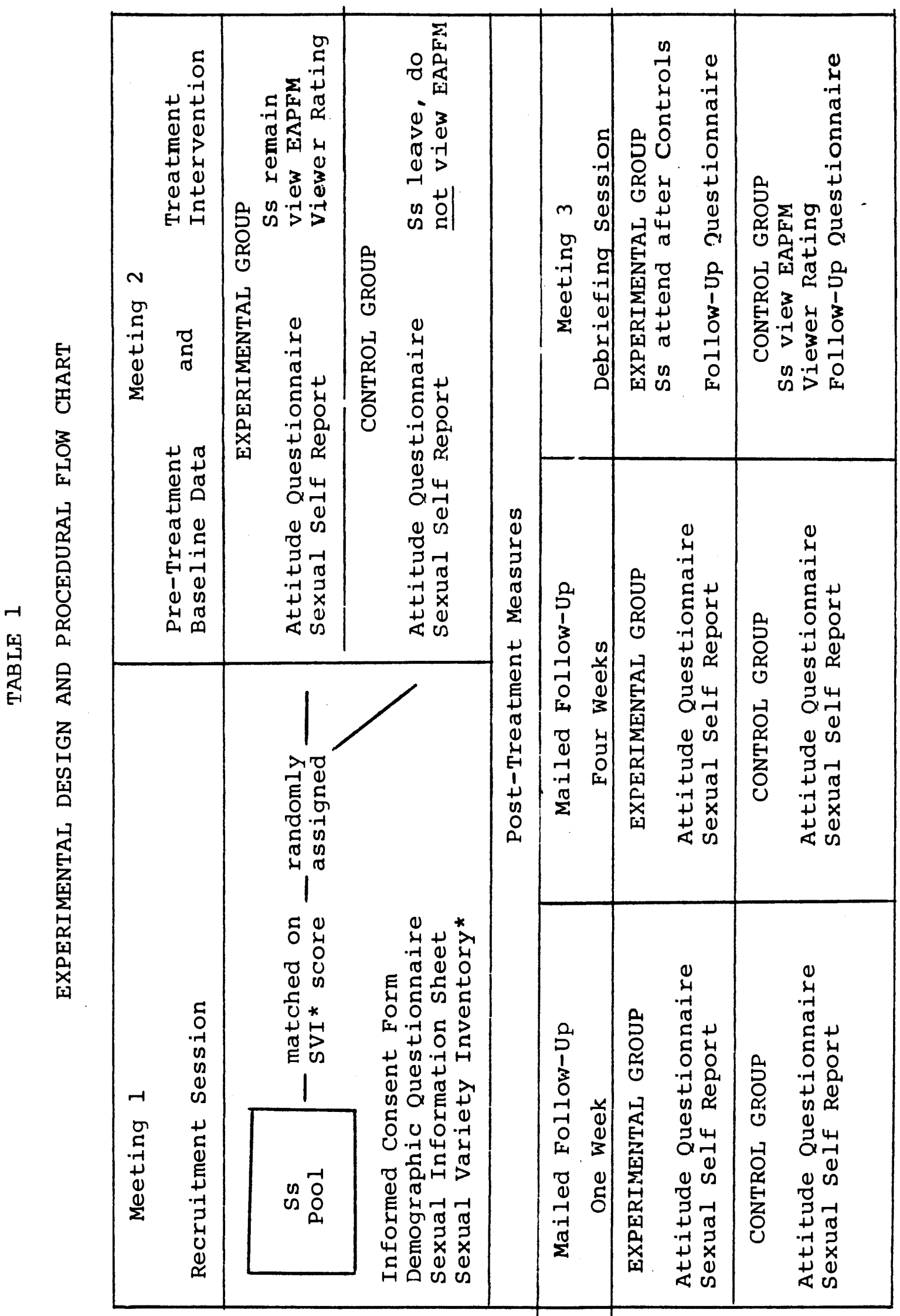


were mailed two sets of questionnaires, both containing an Attitude Toward Masturbation Questionnaire and a Weekly Sexual Self Report Form at a one week and four week interval from this date. Accordingly, post treatment measures reflecting subjects' attitudes, sexual behavior and masturbatory frequency were thereby gathered. Between group comparisons were then made, at week and four weeks after intervention, measuring changes in these variables occurring as a function of the EAPFM alone. In addition to $t$ tests compairing means for two independent samples, a correlational analysis of the data was also performed.

A third or follow-up debriefing meeting was then held. Control subjects $(N=9)$ were assembled first, viewed the EAPFM, completed the Viewer Rating sheet and after a break were joined by subjects from the experimental group $(N=9)$. The Follow-Up Questionnaire was then completed by all subjects $(N=18)$. After the questionnaires were completed, a general question and answer period was held. It was the additional purpose of this meeting to: (1) answer any questions subjects had about the study; (2) to explain the design and intent of the study and (3) to provide for a direct exchange of feelings from subjects in both groups about their involvement as participants in the study. Those subjects unable to attend the debriefing session $(\mathrm{N}=2)$ were contacted by phone.

As a further follow-up measure, telephone contact was made with the University Counseling Center one week and four 
weeks after the second meeting and the debriefing meeting, to determine whether or not, as a result of their participation in the study, any subjects had sought out the counseling services made available to them.

Attrition

A total of thirty two women originally indicated an interest in volunteering as subjects for this study. The experiment began with two groups of 16 matched pairs. Within the first two weeks of the experiment, a total of seven subjects, (four from the experimental and three from the control group) dropped out of the study, leaving 10 intact matched pairs for the duration of the experiment, combined $\mathrm{N}=20$. Unmatched subjects completed the experiment but their responses were not tabulated in the results.

A comparative review of the demographic information on this group of subjects indicated that they tended to be single $(71 \%)$; less likely than the continuing subjects to be in a sexual relationship (718 vs 958); less likely to rate themselves as having a "high" sex drive (0\% vs 35\%); and slightly more likely to rate themselves as being "very" devout ( $14 \%$ vs 10\%). The characteristeristics of the women who dropped out might suggest that participating in sexual research and in a study in which subjects are requested to record sexual behavior may tend to select out more sexually inactive women from participating. 


\section{RESULTS}

Demographic and Sexual Characteristics of subject Sample

The Demographic Questionnaire and the Sexual Information Sheet indicated that female students participating in the study were undergraduates averaging thirty years of age; were predominantly nondevout, sexually experienced, orgasmic and generally personally satisfied heterosexual feminists who were involved in an active sexual relationship with another; tended to live with this intimate/mate, classified themselves as "open and joyful" in their approach to sexuality and assessed themselves as being highly motivated to learn more about increasing their sexual potential. (See Tables $2 \& 3$ ).

Further, these two questionnaires revealed that half of the female subjects were single; half were married. Almost half professed no religious affiliation. Half of these women rated their sex drive as moderate while slightly over half rated their sex drive as being in the "more than moderate" to "high" category. Over half of the sample earned annual yearly incomes in excess of $\$ 10,000 ;$ a sixth earned annual incomes in the $\$ 5,000$ to $\$ 10,000$ ranges and a third of the sample reported earning incomes of under $\$ 5,000$.

Weekly Sexual Self Report forms indicated that women on the average were masturbating twice weekly at baseline, while engaging in cunnilingus or other non-coital sexual stimulation and/or intercourse from four to five times weekly. Over half of these women simultaneously rated each of the sexual behaviors mentioned above as either "extremely" or "very" physically 


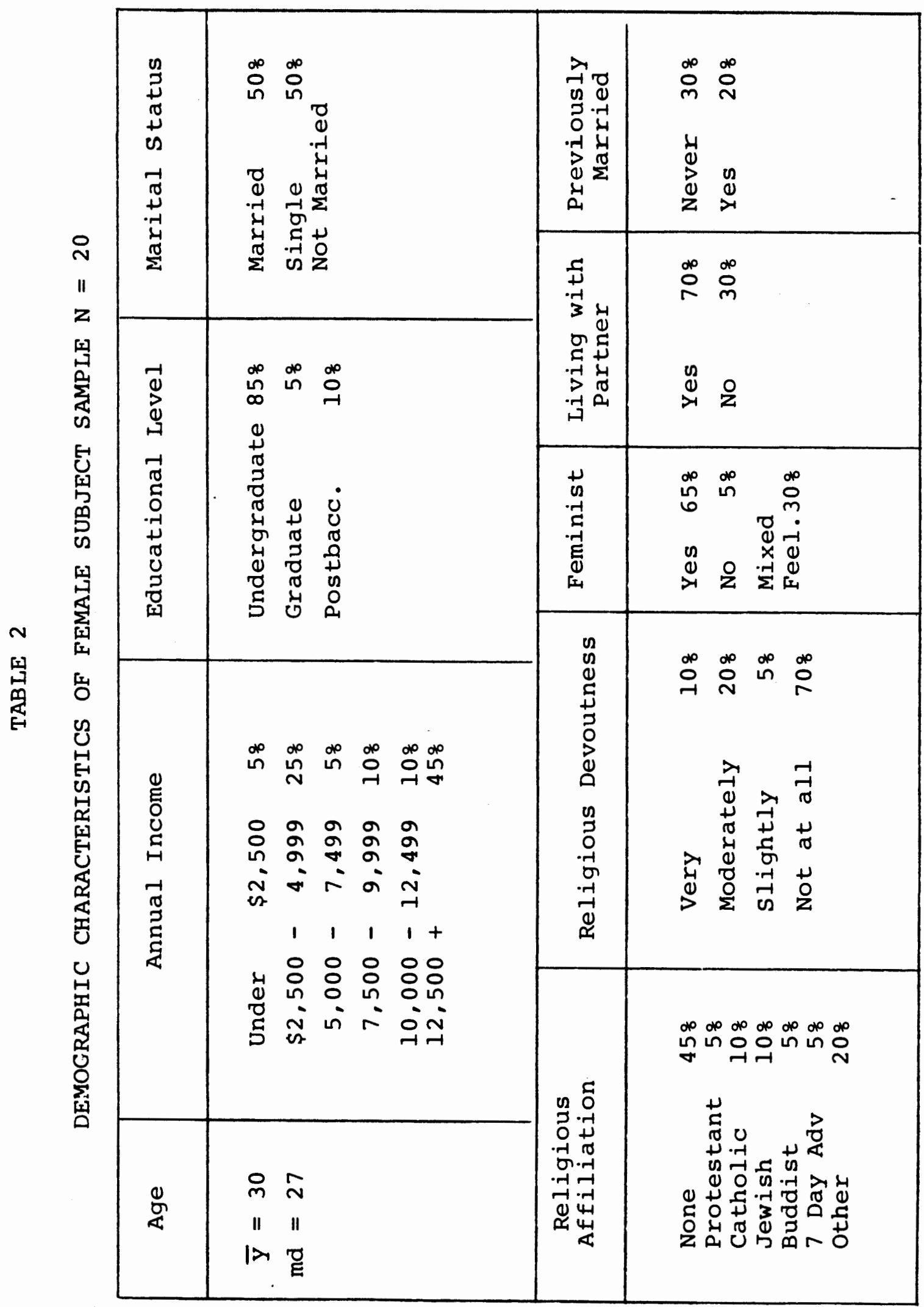




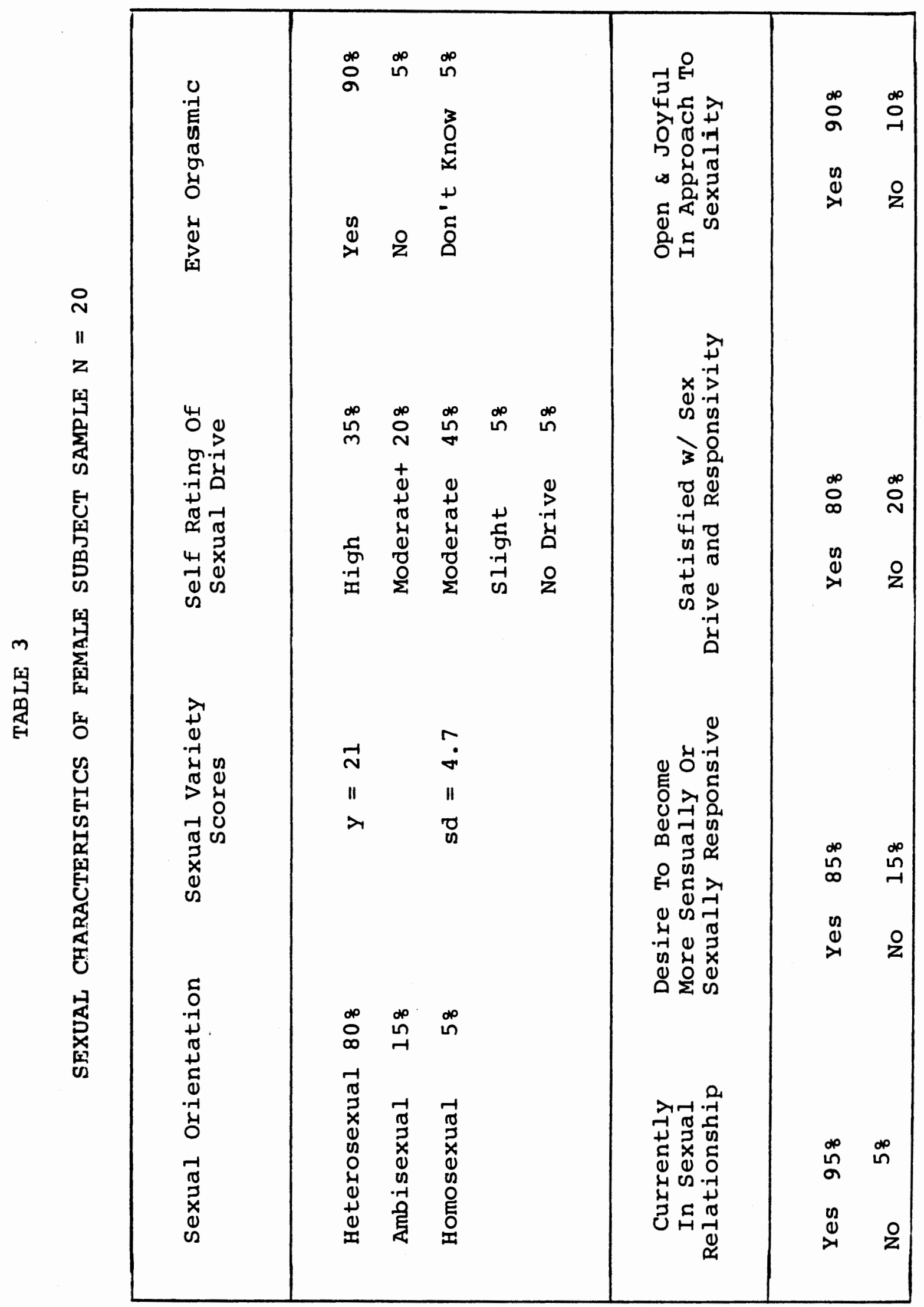


and psychologically pleasurable.

Sexual Variety Inventory scores revealed that subjects averaged a score of 21 out of the 25 possible, indicating a varied sexual repertoire and direct experience with the overwhelming majority of the sexual bahviors listed in the inventory. (see Table 3).

Attitudes Toward Masturbation

Variety of sexual experience, as measured by the Sexual Variety Inventory, was utilized in this study as the variable upon which subjects were matched, utilizing this measure as a predictor of subjects' attitudes toward masturbation.

A review of the closeness of the original subject match on this variable revealed that as a result of this matching procedure, four subject pairs had identical attitude scores, two differed by only one point and the scores of the remaining four pairs differed by no more than four points.

On the Attitudes Toward Masturbation scale, where 150 points marked the most positive attitude toward masturbation possible, female subjects in the combined sample of 20 , averaged a score of 127 at baseline, indicating a predominance of positive attitudes toward masturbation (See Table 4).

Further, it was found that an overwhelming majority of the subjects scored within the top third of the attitude scale, scoring within the 100-150 point range.

Significant correlates. Correlational analysis revealed the finding that positive attitudes toward masturbation were found to be significantly correlated $(r=.67 ; \mathrm{p}<.001)$ with 
variety of sexual experience, as measured by the Sexual Variety Inventory score, such that the more varied the sexual experience of the college women, the more positive their attitudes toward masturbation. This result validates similar findings in the literature, such as Mosher's examination of the attitudes toward masturbation of college women in a coed sample (Mosher, 1973; Abramson \& Mosher, 1975), in which negative attitudes toward masturbation were found to be correlated with inhibited sexual behavior.

Additionally, it was discovered that womens' attitudes toward masturbation and their ratings of their own sex drive were positively correlated $(r=.63 ; p .001)$, such that the more highly a woman rated her sex drive, the more the tendency for her to feel positively toward or to reflect positive attitudes toward masturbation. This finding might suggest that as a woman sees herself as a sexual being, as revealed by self rating of sexual drive, she also tends to have positive attitudes toward masturbation as a sexual behavior (See Table 5).

\section{Post Treatment Measurement: Differences Between Groups,}

Week 1 and Week 4. At baseline, the mean attitudes for both the experimental and control groups were identical ( $\bar{y}=127)$, (See Table 4).

It was hypothesized in this study that in comparison to untreated control subjects, women in the experimental group exposed to the EAPFM would likely demonstrate a measurable increase in positive attitudes toward masturbation.

A $t$ test comparing means for two independent samples 
was conducted between the experimental and control groups at week $1(t(18)=.07)$ and week $4(t(18)=.10)$ following treatment. Results indicated that the experimental and control groups were not significantly different in attitudes toward masturbation at week 1 or at week 4 .

\section{Frequency of Masturbation}

As indicated on the Weekly Sexual Self Report form, female subjects in the combined sample of 20 , reported masturbating on the average of twice a week at baseline.

Significant Correlates. Correlational analysis revealed the finding that frequency of masturbatory behavior was significantly positively correlated $(r=.48 ; p<.05)$ with sexual variety as measured by the Sexual Variety Inventory scale, such that the more frequent the masturbatory behavior of the female subject, the more sexually experienced she tended to be. This result is consistent with findings relating increased masturbatory frequency with increased sexual experience among college women (Abramson \& Mosher, 1975).

Additionally, it was discovered that the frequency of female masturbatory behavior was significantly correlated $(r=.59 ; p<.01)$ with subjects self rating of sexual drive, such that the higher the rating of the females sex drive, the higher her masturbatory frequency per week. (See Table 5). This finding would be in keeping with the findings of previous sexual researchers, (Kinsey et al., 1948; Masters 


\section{TABLE 4}

\section{ATTITUDES TOWARD MASTURBATION AND \\ WEEKLY FREQUENCY OF MASTURBATION}

OVER TIME BY CONDITION

\begin{tabular}{|c|c|c|}
\hline \multicolumn{3}{|c|}{ COMBINED SAMPLE $\mathrm{N}=20$} \\
\hline $\begin{aligned} \bar{y} & =127.0 \\
\text { sd } & =16.5\end{aligned}$ & & $\begin{aligned} \bar{y} & =2.0 \\
s d & =8.1\end{aligned}$ \\
\hline Baseline Attitudes & $\begin{array}{l}\text { Attitudes } \\
\text { Week } 1\end{array}$ & $\begin{array}{l}\text { Attitudes } \\
\text { Week } 4\end{array}$ \\
\hline \multicolumn{3}{|c|}{ EXPERIMENTAL GROUP $\mathrm{N}=10$} \\
\hline $\begin{aligned} \bar{y} & =127.0 \\
\text { sd } & =19.1\end{aligned}$ & $\begin{aligned} \bar{y} & =129.0 \\
s d & =10.6\end{aligned}$ & $\begin{aligned} \bar{y} & =129.5 \\
\text { sd } & =11.5\end{aligned}$ \\
\hline \multicolumn{3}{|c|}{ CONTROL GROUP $\mathrm{N}=10$} \\
\hline $\begin{aligned} \bar{y} & =127.5 \\
\text { sd } & =14.4\end{aligned}$ & $\begin{aligned} \bar{y} & =128.5 \\
s d & =10.7\end{aligned}$ & $\begin{aligned} \bar{Y} & =131.0 \\
\text { sd } & =11.7\end{aligned}$ \\
\hline Baseline Frequency & $\begin{array}{l}\text { Frequency } \\
\text { Week } 1\end{array}$ & $\begin{array}{l}\text { Frequency } \\
\text { Week } 4\end{array}$ \\
\hline \multicolumn{3}{|c|}{ EXPERIMENTAL GROUP $\mathrm{N}=10$} \\
\hline $\begin{aligned} \bar{y} & =2.1 \\
s d & =1.7\end{aligned}$ & $\begin{aligned} \bar{y} & =3.0 \\
\text { sd } & =2.7\end{aligned}$ & $\begin{aligned} \bar{y} & =4.0 \\
s d & =6.5\end{aligned}$ \\
\hline \multicolumn{3}{|c|}{ CONTROL GROUP $\mathrm{N}=10$} \\
\hline $\begin{aligned} \bar{y} & =2.3 \\
s d & =2.3\end{aligned}$ & $\begin{aligned} \bar{y} & =3.0 \\
s d & =4.5\end{aligned}$ & $\begin{aligned} \bar{y} & =.9 \\
s d & =1.1\end{aligned}$ \\
\hline
\end{tabular}




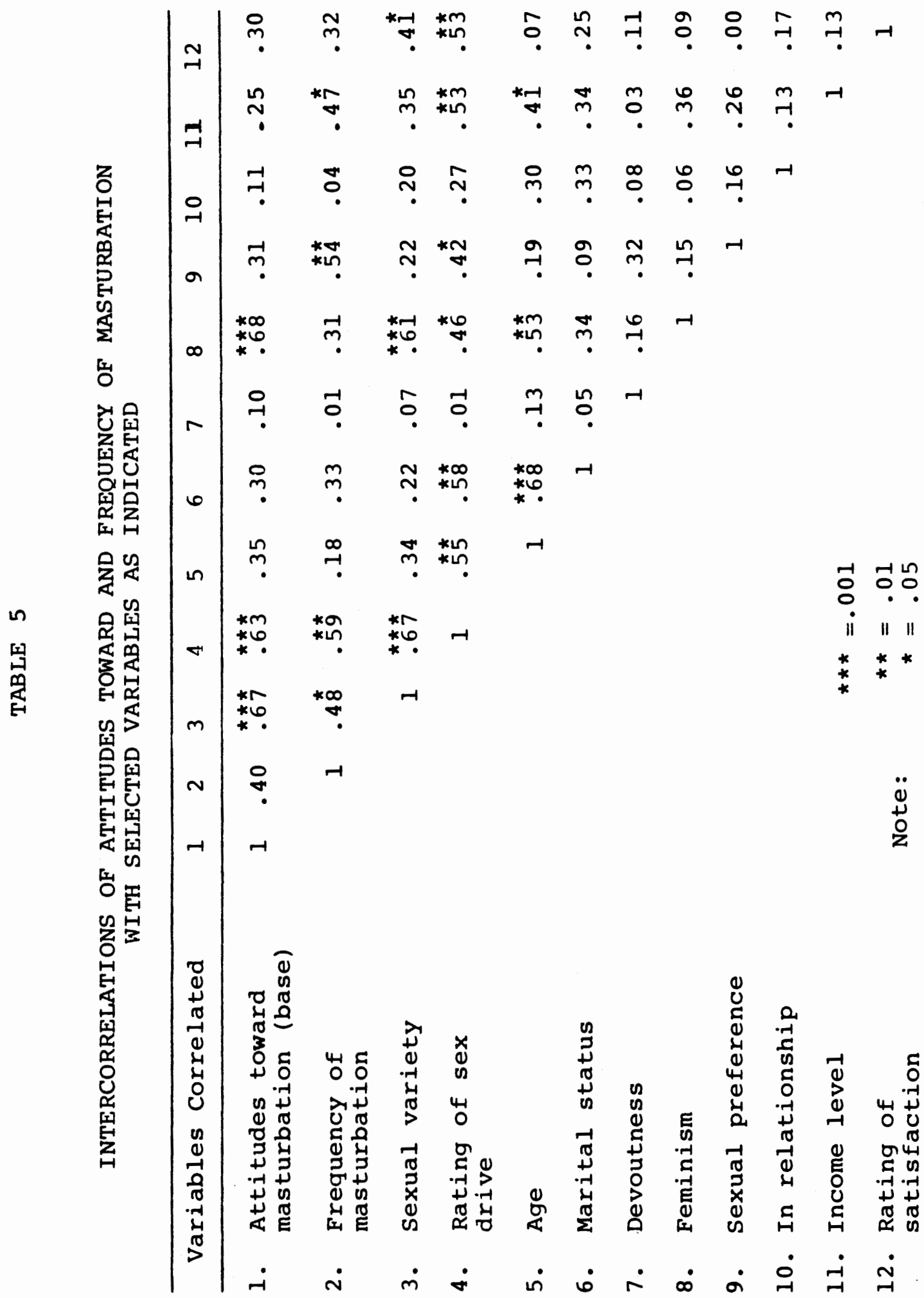


and Johnson, 1966; Barbach, 1974; and others) suggesting that masturbation can be viewed as a viable index of a woman's sexual drive or urge to be sexual independently of a partner.

Post Treatment Measurement: Differences Between Groups, Week 1 and Week 4. At baseline the mean weekly masturbatory frequency for the experimental and control groups were the same $(y=2)$. (See Table 4).

It was hypothesized in this study that in comparison to untreated control subjects, women in the experimental group exposed to the EAPFM would likely demonstrate a significant increase in masturbatory frequency. A $t$ test, compairing means for independent samples was conducted between the experimental and control groups at both of the posttreatment times. Results indicated that the experimental and control groups were not significantly different in masturbatory frequency at week $I(t(18)=0)$ or at week $4(t(18)=$ $1.49)$.

Novel Masturbatory Behavior Demonstrated

In addition to a belief that there would be a demonstrable difference between groups in attitudes and masturbatory frequency, it was also hypothesized that novel, or first-time self stimulatory behavior might be exhibited during the course of the experiment as imitative of the behaviors modeled in the EAPFM, by the subjects in the experimental group exposed to this material. This proved to be the case. 
Four novel sexual behaviors were recorded for three subjects in the experimental group while no such behavior was documented among subjects in the control group. The only female subject in the sample, $\mathrm{N}=20$, who had, "never before" attempted masturbation, masturbated for the first time in her life during the first week of the experiment after viewing the EAPFM. Another subject, also one week after viewing this presentation, took the time to view her body carefully in a mirror (as modeled in the film) for the first time.

This subject and one other subject two weeks after the EAPFM respectively, reported stimulating their own genitals during sexual interaction with their sexual partner for the first time in their lives. These women were two out of 10 women in the experimental group, and 2 out of 12 in the combined sample of 20 who never before engaged in this behavior.

Subject Ratings of the Educational Audiovisual Presentation on Female Masturbation, EAPFM

Tabulation of the Viewer Rating sheet revealed that subjects $(\mathrm{N}=18)$ expressed a very positive reaction to both the entire educational package and to each of its three component parts.

In rating the comprehensive EAPFM along three criteria, a majority of female respondents (6I.9\%) rated the EAPFM as being: (1) "very" to "extremely" informative; (2) assessed it as being "not at all" anxiety producing (698); and (3) indic- 
ated that their overall reaction to the presentation as a whole was "very" to "extremely" positive (61.68).

Similarly, a majority of over 508 of respondents respectively rated parts I, II, and III independently as being "very" to "extremely" informative and "not at all" anxiety producing.

In rating the three parts of the EAPFM according to these criteria, some preferences and differences emerged.

In evaluating the informativeness of each part of the EAPFM, 708 of subjects rated "Reaching Orgasm" as being "very" to extremely" informative; 628 rated the "Lecture on Masturbation similarly, while 548 rated "Speaking out" in the same way.

In assessing the anxiety producing nature of each part, 85 of the respondents indicated that the lecture was "not at a11" anxiety producing; fewer subjects, constituting 788 of the respondents indicated that the peer discussion of masturbation and the film modeling masturbation were equally anxiety free. Conversly, while $15 \%$ of the raters assessed the lecture and the film as being only "a little" or "moderately" anxiety producing, and $15 \%$ indicated they felt the discussion was "very" anxiety producing, 7.6 or $8 \%$ of the subjects rated the film as being "extremely" anxiety producing. This was the only such high rating of anxiety in the study.

This is an interesting finding when it is noted that in assessing the third criterion, subjects' overall reaction to 
each part of the presentation, $78 \%$ of female respondents rated themselves as having a "very" to "extremely" positive reaction to the film. Slightly fewer respondents, 628 , indicated having a similar reaction to the peer discussion, while $46 \%$ indicated that they had the same reaction to the lecture.

\section{Observations}

Subject Awareness of Demand Characteristics. As revealed by the Follow-Up Questionnaire, of the $75 \%$ of the subjects $(\mathrm{N}=18)$, who claimed to have an "accurate perception of the design and purpose of the current study", it was determined from two different questions that in fact, only $30 \%$ of the sample had a true working knowledge of the experiment. When asked directly whether or not they felt their knowledge biased their objectivity in responding, $100 \%$ of the female respondents indicated that it did not.

Effects of Recording Sexual Behavior. When asked whether or not recording sexual behavior influenced the frequency of engaging in those sexual behaviors being recorded, a majority (65\%) indicated that there was no effect on frequency. When subjects were asked whether or not they were personally affected by having to record their sexual behavior during the course of the study, 358 of the respondents indicated that they felt "no effects"; $30 \%$ identified that there were "some", largely short-term situational effects (i.e. initial hesitation in filling out the forms for the first time; becom- 
ing "bored" with completing them; arousing another's initial curiosity, etc.); and $35 \%$ cited "particularized" effects they were aware of after they had begun filling out forms.

Self Rated Impact of Study on Subjects. One hundred percent of respondents completing the Follow-Up Questionnaire $(\mathrm{N}=18)$, indicated that there had been "no" negative impact on their routine sexual behaviors or attitudes or on their routine masturbatory behavior or on their attitudes toward masturbation as a result of their participation in the current study. Ninty five percent of respondents similarly recounted "no" negative effects of this study on themselves as subjects or on their relationships with intimate others.

One subject, however, citing her own negative reaction to the film as the source of discomfort, indicated that she was affected personally in a negative manner by being a participant in the current study. Another subject cited an unanticipated interpersonal conflict when, as a function of the education she received as a subject, she found her intimate to have "very closed-minded attitudes".

A majority (708) of female respondents indicated that "yes" the experiment had had a positive and/or desirable impact on them personally as subjects. Half of the respondents responded "yes" and half answered "no" to the question of whether or not participation in the current study had had a positive impact on their routine sexual behaviors and attitudes toward masturbation or on their own masturbatory be- 
havior. (See Table 6 for open-ended responses of subjects). Subject Use of Available Follow-Up Counseling Services. Counseling services were made available to subjects through the Portland State University Counseling Center, should any subject wish them for whatever reason as a follow-up to her involvement in the current study. In a follow-up telephone check conducted one week and four weeks after the second and debriefing meetings, it was concluded that only a total of two subjects had sought such services on a limited, one-toone visit basis. 


\section{TABLE 6}

\section{OPEN ENDED RESPONSES OF SUBJECTS IDENTIFYING EFFECTS OF EAPFM AND OVERALL PARTICIPATION IN RESEARCH}

Reactions to "Lecture on Masturbation", Part I EAPFM:

1."I learned alot about masturbation that I hadn't known before".

2."I was surprised by some of the research. Having an orgasm through masturbation always worked for me when straight intercourse wouldn't; its nice to know that that is true for other women too".

3. "Well, I sure didn't have my facts straight. I thought masturbation would make you sick or screw you up somehow".

4. "I knew alot of the information, but hearing it all at one time and how it related to orgasms had a different impact on me".

5. "The myths people believed were amazing".

Reactions to "Speaking Out", Part II EAPFM:

1."I had a strong good reaction to the videotape, hearing women discussing sexuality and masturbation in a positive way".

2."I enjoyed the feeling of information and helpfulness expressed by most of the women on the tape and the problems they encountered. I could identify with what they said".

3." The videotape helped me to know what to say to my teenage daughter"

Reactions to "Reaching Orgasm", Part III EAPFM:

1."'Reaching Orgasm' was very enjoyable. I enjoyed seeing the close ups of the woman's genitals in the film".

2."I enjoyed this film, it gave me something to compare myself with". 
TABLE 6 Continued

3."I was very aroused by the film. It's good to see how close her reactions were to mine".

4." I found the woman in the film to be very unattractive. I was very uncomfortable watching her, and thought she was absolutely repulsive".

Positıve Effects Identified as affecting Subjects Personally

1. "Going through the questions during the week had a positive effect. It made me aware of the incongruity between my personal philosophy and my behavior and motivated me to address that".

2. "Being in the study made me think about myself and sex and masturbation more than I otherwise would have. I believe as a result, I've become more aware of myself sexually".

3. "I feel better about myself and am more honest in my sexual behavior with myself".

4. "I had a feeling of satisfaction from participating in the research... The fact that someone was researching this subject made me feel good".

5. "I feel personally happier because of this experience" Negative Effects Identified as affecting Subjects Personally

1. "I didn't like watching an ugly woman masturbate".

Positive Effects Identified as affecting Subjects Masturbatory Attitudes or Behavior

1. "I feel less inhibited about masturbating during intercourse".

2. "Masturbation has become more acceptable to me personally".

3. "I find I am now able to be more honest and open about masturbation". 
TABLE 6 Continued

4. "I understand more about it now; especially the misconceptions".

5. "I am now less inhibited about masturbation".

6. "It's good for me to know that other women get off on it too; that's comforting".

7. "I see masturbation now as both good and necessary for me".

Positive Effects Identified as affecting Subjects Other Sexual Behavior and Sexual Behavior with a Partner

1. "I feel more aware of my potential responsiveness and can try new things."

2. "I bought a book for further information".

3. "I have noticed an increase in my sexual activities".

4. "I find I am more open with my friend about my sexuality".

5. "It has offered me an opportunity to understand myself better and to relate better".

6. "I feel better about myself and am more honest with my lover".

7. "I have talked to my lover about some things I have never mentioned before".

8. "My partner is enjoying my increased responsiveness".

Negative Effect Identified as affecting Subjects Other Sexual Behavior and Sexual Behavior with a Partner

1. "I find my lover to have very closed-minded attitudes". 


\section{DISCUSSION}

The current study had several purposes. It was designed to develop an educational tool on female masturbation capable of reaching a wide audience of women with accurate and complete information on female masturbation. Further, it was designed to provide preliminary validation for the further educational usefulness of this tool and to assess its potential ability to alter negative attitudes toward masturbation and to improve sexual functioning in women by the disinhibition of masturbatory behavior.

The educational audiovisual presentation on female masturbation, EAPFM, developed for this study would seem to have much to reccomend it.

In keeping with Robinson's research (1974) in which he concluded that focused sexual information more effectively facilitates the learning of specific sexual behaviors than does the communication of a more generalized sexual informational base, one of the advantages of the EAPFM is its specificity and the comprehensive congruent interrelatedness of the information contained in its three component parts.

While filmed peer discussions of sexual issues have recently become available through nationalized clearing houses, resource films of this genre addressing the issue of female masturbation typically use informal, spontaneous and inherently randomized dialogue as a means of communicating information to the viewer. A limitation here has 
frequently been the lack of structure and the corresponding lack of control in dispensing comprehensive information. The result is that several issues of significance have not consistently been addressed. The peer discussion of female masturbation designed for this study attempted to control for the inclusion of this information by identifying important informational needs in advance and by structuring responses in a diadic interview format, to consistently solicit and incorporate this information.

Additionally, while films modeling specific masturbatory behavior directly have recently been made available, they have typically been shown independently of other audiovisual aids in sexual research (LoPiccolo \& Lobitz, 1972; Heiby \& Becker, 1980). Other than the model developed and tested by Annon (1974) and further implemented by Robinson (1974), sexual research efforts have generally not attempted to design and implement an educational model that would broaden this direct sexual modeling focus and incorporate other observational learning techniques through the medium of video or film to address other informational needs by debunking myths, correcting misconceptions and attempting to promote more positive attitudes toward female masturbation and a better overall understanding ot its role in sexual life. By design the current study expanded this focus by additionally offering audiovisual components focused on providing accurate information, peer modeling, discussion and 
permission, as adopted from the PLISSIT model proposed by Annon (1971) and the dual attitudinal and behavioral focus of Robinson (1974) who found that changes in attitudes toward masturbation and increased masturbatory behavior were more effectively promoted by the combination of the two than by the informational/attitudinal series alone.

Another strength of the current research is the fact that it sought to measure subjects' individual reactions to the EAPFM, and provided for an individualized rating of each part of the three part educational package.

These ratings demonstrate a positive overall reaction to the EAPFM and are very encouraging indicators of its initial acceptance by this female audience. The ratings used here, however, do represent relatively simple, preliminary information for the educational usefulness of this tool and would not necessarily be reflective of its similar acceptance by a different viewing audience.

As an interesting observation, the fact that some viewer anxiety was noted after exposure to the sexually explicit film modeling masturbation and the fact that it prompted some negative commentary was consistent with the findings of Hieby and Becker (1980). They found that after exposure to a similar film, college women similarly commented that they found the female model hard to relate to or otherwise rated her appearance as it was congruent or incongruent with their own individualized image of beauty and attractiveness. 
In measuring the EAPFM's potential for promoting positive attitudes toward masturbation and/or increasing masturbatory behavior, the data from the present study did not indicate a significant difference between the control and experimental groups. Although this was the case, the EAPFM did appear to be instrumental in prompting the acquisition of new masturbatory behaviors to the sexual repertoire of 308 of this group of subjects.

The finding that the EAPFM did not promote significant increases in positive attitudes toward masturbation or frequency of masturbation among women in the experimental group is believed to be a function of the sample rather than the educational instrument itself.

Subjects in the present sample, unlike females in the more general population of women in the United States (Hite, 1976), possessed high positive attitudes toward masturbation, with the majority scoring within the top third of the measuring scale. A relatively high average weekly masturbatory frequency was exhibited in baseline data; additionally, sexual interaction with partners, was reported on an average five out of seven days. Combined, these baseline values were sufficiently high enough to create a "ceiling effect" in the study's ability to clearly measure and document significant increases in either the attitudinal or frequency variables recorded.

As an interesting observation, the finding that female 
subjects in this study masturbated on the average of twice weekly, or eight times a month, duplicated the finding of Arafat and cotton (1974) in which 338 of 205 randomly selected college females aged 17-30, similarly reported masturbating twice weekly. This finding represents eight times the monthly masturbațory frequency recorded for unmarried females in the random sampling of the female population conducted by Kinsey et al (1948), some thirty years ago.

of additional interest in this study was the finding that positive attitudes toward masturbation were significantly correlated with the variety of sexual experience of female subjects in a manner which duplicated the results of previous research. Studies of college females using the same attitude scale (Mosher, 1973; Abramson \& Mosher, 1975) found negative attitudes toward masturbation to be correlated with inhibited sexual behavior.

Similarly, correlational analysis revealing that the frequency of masturbatory behavior was significantly positively correlated with sexual variety was consistent with other work relating increased sexual experience with increased masturbatory frequency among college women (Abramson \& Mosher, 1975). 


\section{CONCLUSIONS AND RECOMMENDATIONS}

It appears that one of the major contributions of this research is the development of a three part Educational Audiovisual presentation on Female Masturbation, EAPFM. The EAPFM was well received by subjects, was rated as being both informative and positive in its impact on female viewers and proved capable of promoting new sexual behaviors among women in a nonclinical college population.

A limitation of the current study is its relatively small population and the initially biased nature of the sample. More information is needed about the potential use of the EAPFM with more diverse populations of females.

To additionally and more specifically assess the further educational usefulness of this tool, additional research is indicated. Such research would need a larger, more diverse sample of women. Subjects might be recruited through large women's organizations which serve diverse populations, such as the Y.W.C.A., the Oregon Women's Political Caucus, the Jewish Women's League, etc. Assembling a sample representative of the wider population of American women remains a great difficulty.

The rating system should be revised to provide for a variable rating system which would more narrowly focus on the educational impact of the EAPFM. This rating system could be devised from those educational components deliberately included in the educational model. For example, the assessment of 
the EAPFM could be improved by providing for a rank-ordered assessment of each component relative to one another and by building into the measurement more specific indices of what was "most informative" or "least informative", etc., and why. One final point is important. A limit on the practical effectiveness of the EAPFM comes from its limitations in researching sexual behavior among women. Ultimately, only women who agree, are motivated or volunteer to view sexually explicit material and/or those who are willing to deal directly with the subject of female masturbation will encounter the EAPFM, or any educational tools like it. As the subjects who dropped out of the study serve to illustrate, this means that the group of women who are most inhibited in sexual response are the least likely to participate in research using an educational tool, like the EAPFM, aimed at improving their acceptance of female masturbation and its incorporation into female sexual expression. This effect is apparent in the sample collected for the present study. It remains a major unsolved problem in research of this type. 


\section{BIBLIOGRAPHY}

Abramson, P. R. The relationship of the frequency of masturbation to several aspects of behavior. Journal of Sex Research, 1973, 9, 132-142.

Abramson, P. R., Goldberg, P. A. \& Mosher, D. L. Experimenter effects on responses to explicitly sexual

stimuli. Journal of Research in Personality, 1975, 9, 136-146.

Abramson, P. R. \& Mosher, D. L. Development of a measure of negative attitudes toward masturbation. Journal of Consulting and Clinical Psychology, $1975,43,(4)$, 485-490.

Amoroso, D. M. \& Brown, M. Problems in studying the effects of erotic material. Journal of Sex Research, 1973, 9, (3), 187-195.

Annon, J. S. The extension of learning principles to the analysis and treatment of sexual problems. Doctoral Dissertation, University of Hawaii: Ann Arbor, Michigan. University Microfilms, 1971, no. 72-290.

Annon, J. S. The therapeutic use of masturbation in the treatment of sexual disorders. In R. Rubin, J. Brady \& J. Henderson (Ed.), Advances in Behavior Therapy: Volume 4. New York: Academic Press, 1973.

Annon J. S. The Behavioral Treatment of Sexual Problems: Volume 1, Brief Therapy. Honolulu: Kapiolani Health Services, 1319 Punahou Street, 96814, 1974.

Annon, J. A. The PLISSIT model: A proposed conceptual scheme for the behavioral treatment of sexual problems. Paper presented at the annual meeting of the society for the scientific study of Sex, Las Vegas, November, 1974.

Anonymous. Onania, or the Heinous Sin of Self-Pollution And All Its Frightful Consequences, in Both Sexes, Considered With Spiritual and Physical Advice to Those Who Have Already Injur'd Themselves by This Abominable Practice, to which is Subjoin'd a Letter From a Lady to the Author, Concerning the Use and Abuse of the Marriage Bed, With the Author's Answer. London: 4 th edition, 1726 .

Arafat, I. \& Cotton, W. L. Masturbation practices of males and females. Journal of Sex iesearch, 1974, 10, (4), 293-307. 
Bandura, A., Blanchard, E. \& Ritter, B. Relative efficacy of desensitization and modeling approaches for inducing behavioral, affective and attitudinal changes. Journal of Personality and Social Psychology, 1969, $13,173-199$.

Bandura, A. Psychotherapy based upon modeling principles. In A. Bergin \& S. Garfield (Ed.), Handbook of Psychotherapy and Behavior Change. New York: John Wiley \& Sons, Inc., 1971.

Bandura, A., Jeffery, R. W. \& Wright, C. I. Efficacy of participant modeling as a function of response induction aids. Journal of Abnormal Psychology, 1974, 83, 56-64.

Bandura, A. \& Menlove, F. I. Factors determining vicarious extinction of avoidance behavior through symbolic modeling. Journal of Personality and Social Psychology, 1965,2 , 698-705.

Barbach, I. G. Group treatment of preorgasmic women. Journal of Sex and Marital Therapy, 1974, 2, 139-154.

Barbach, L. G. For Yourself: The Fulfillment of Female Sexuality. New York: Doubleday \& Co., Inc., 1975.

Bardwich, J. M. Psychology of women: A Study in BioCultural conflicts. New York: Harper \& Row, 1971.

Bardwich, J. M. Readings on the Psychology of women. New York: Holt \& Rinehart, 1972 .

Bardwich, J. M. In Transition: How Feminism, Sexual Liberation and the Search for self Fulfillment Have Altered America. New York: Holt \& Rinehart, 1978.

Bentler, P. M. Heterosexual behavior assessment. Behavioral Reaearch and Therapy, $1968,6,21-30$.

Bentler, P. M. \& Peeler, W. H. Models of female orgasm. Archives of Sexual Behavior. 1979, 8, 405-423.

Berne, E. The problems of masturbation. Diseases of the Nervous System, 1944, 5, 301-305.

Boston Womens Health Collective. Our Bodies Our Selves, A Book by and for Women. New York: Simon \& Schuster, 1976 .

Brady, J. P. \& Levitt, E. E. The scalability of sexual experiences. Psychological Record, 1965, 15, 275279 . 
Brecher, R. \& Brecher, E. (Ed.). An Analysis of Human Sexual Response. New York: Signet, 1966.

Burhans, D. T. The attitude-behavior discrepancy problem: revisited. Quarterly Journal of Speech, 1971, 75, 50-59.

Burrows, G. M. Commentaries on the causes, etc., of insanity. London, 1828 .

Carpenter, C. R. Sexual behavior of free ranging rhesus monkeys (Macaca mulatta) I. Specimens, procedures and behavioral characteristics of estrus II. Periodicity of estrus, homosexual, autoerotic and non-conformist behavior. Journal of Comparative Psychology, 1942, XXXIII, 113-142; 143-162.

Clifford, R. Development of masturbation in college women. Archives of Sexual Behavior. 1978, 7, 559-573.

Clower, V. Significance of masturbation in female sexual development and function. In Marcus \& Francis (Ed.), Masturbation from Infancy to Senescence. New Jersey: Library of Human Behavior, 1975.

Comfort, A. Joy of Sex: A Gourmet Guide to Love-Making. New York: Simon \& Schuster, 1972.

Comfort, A. More Joy of Sex: A Lovemaking Companion to Joy of Sex. New York: Simon \& Schuster, 1973.

Cox, S. Female Psychology: The Emerging Self. Chicago: Science Research Associates, Inc., 1976.

Dearborn, L. Autoeroticism. In A. Ellis \& A. Abarbanel (ed.), The Encyclopedia of Sexual Behavior, Volume 2. New York: Hawthorne Books, 1961 .

Dillehay, R. C. On the irrelevance of the classical negative evidence concerning the effect of attitudes on behavior. American Psychologist, 1973, 28, 887-891.

Darling, F. F. A Herd of Red Deer. London: Oxford University Press, 1937 .

Dodson, B. Liberating Masturbation, a Meditation on Self Love. New York: Body Sex Designs, 1974 .

Ellis, A. \& Abarbanel, A. The Encyclopedia of Sexual Behavior, Volume 1. New York: Hawthorne Books, Inc., $1964,204-216$. 
Eyer, A. Clitoridectomy for the cure of masturbation in girls. Internal Medicine Magazine, 1894, 3, 259.

Feingold, L. An illustration of the behavioral therapy approach in the treatment of social and sexual problems. Pennsylvania Psychiatric Quarterly, $1966,6,3-\overline{19}$.

Fishbein, M. Attitudes and the prediction of behavior. In Fishbein (Ed.), Readings in Attitude Theory and Measurement. New York, 1967.

Flanders, J. P. A review of research on imitative behavior. Psychological Bulletin, 1968, 69, 316-337.

Flood, E. An appliance to prevent masturbation. Boston Medical and Surgical Journal. 1888, CXIX, 34 .

Ford, C. S. \& Beach, F. A. Patterns of Sexual Behavior. New York: Harper \& Row, 1951 .

Francis, J. J. \& Marcus, I. M. Masturbation from Infancy to Senescence. New York: International Universities Press, 1975.

Franks, C. M. (Ed.), Conditioning Techniques in Clinical Practice and Research. New York: Springer, 1964.

Franks, C. M. (Ed.), Behavior Therapy: Appraisal and Status. New York: McGraw-Hill, 1969.

Franks, C. M. \& Wilson, G. T. (Ed.), Annual Review of Behavior Therapy: Theory and Practice: 1973. New York: Brunner/Mazel, 1973.

Gardner, G. E. Night terrors and the mutilation threat. Psychoanalitic Review, 1932, 182-199.

Greenbank, R. K. Are medical students learning psychiatry? Medical Journal, 1961, 64, 989-992.

Greenberg, J. S. \& Archambault, F. X. Masturbation, selfesteem and other variables. Journal of Sex Research, $1973,9,41-51$.

Hare, E. H. Masturbatory insanity: the history of an idea. Journal of Mental Science, 1962, 2-25.

Heiby, E. \& Becker, J. Effect of filmed modeling on the self reported frequency of masturbation. Archives of Sexual Behavior. 1980, 9, 115-121. 
Heiman, J., LoPiccolo, L. \& LoPiccolo, J. Becoming Orgasmic: A Sexual Growth Program for Women. New Jersey: Prentice Hall, Inc., 1976.

Hite, S. The Hite Report; A Nationwide Study on Female Sexuality. New York: MacMillan \& Co., 1976.

Hoon, E. \& Hoon, P. Styles of sexual expression in women: clinical implications of multivariate analysis. Archives of Sexual Behavior, 1978, 7, 105-116.

Hubbard, S. An overview of female sexuality. The Humanist, $1976,4,9-19$.

Hunt, M. Sexual Behavior in the 1970's. New York: Playboy Press, 1974, 65-105.

Huschka, M. The incidence and character of masturbation threats in a group of problem children. Psychoanalytic Quarterly, 1938, 7, 338-356.

Hutchinson, J. On circumcision as preventive of masturbation. Archives of Surgery, 1890, 266-269.

Ince, L. P. Behavior modification of sexual disorders. American Journal of Psychotherapy, 1973, 17, 446451 .

James, W. H. The reliability of the reporting of coital frequency. Journal of Sex Research, 1971, 7, 312314 .

Kaats, G. R. \& Davis, K. E. Effects of volunteer biases in studies of sexual behavior and attitudes. Journal of Sex Research, 1971, 7, 26-34.

Kaplan, H. S. The New Sex Therapy: Active Treatment of Sexual Dysfunction. New York: Times Books, 1974.

Katchadourian, H. A. \& Lunde, D. T. Fundamentals of Human Sexuality. New York: Holt, Rinehart \& Winston, Inc., $1972,211-233$.

Kegel, A. H. Sexual functions of the Pubococcygeus Muscle. Western Journal of Surgery, 1952, 60, 521-524.

Kerr, C. Sex for Women who want to Have Fun and Loving Relationships With Equals. New York: Grove Press, Inc., 1977, 119-238.

Kiesler, C. A., Collins, B. E. \& Miller, M. Attitude Change: A Critical Analysis of Theoretical Approaches. New York, 1969. 
Kinsey, A. C., Pomeroy, W. B., Martin, C. E., \& Gebbhard, P. H. Sexual Behavior in the Human Female. Philadelphia: W. B. Saunders, 1953.

Kohlenberg, R. J. Directed masturbation and the treatment of primary orgasmic dysfunction. Archives of Sexual Behavior, $1974,3,350-355$.

Kraft, T. Desensitization and the treatment of sexual disorders. Journal of Sex Research, 1969, 5, 130134 .

Kronhausen, E. \& Kronhausen, P. The Sexually Responsive Woman. New York: Grove Press, Inc., 1964 .

Lazarus, A. A. \& Rachman, C. The use of systematic desensitization in psychotherapy. In H. J. Eysenck (Ed.), Behavior Therapy and the Neuroses. New York: Pergamon, 1960 .

Lazarus, A. A. A Case of pseudonecrophilia treated by behavior therapy. Journal of Clinical Psychology, $1968,24,(1), 113-115$.

Lehman, R. E. The disinhibiting effects of visual material in treating orgasmically dysfunctional women. Behavioral Engineering, $1974,1,1-3$.

Lobitz, C. W. \& LoPiccolo, J. New methods in the behavioral treatment of sexual dysfunction. Journal of Behavioral Therapy and Experimental Psychiatry, 1972, 3, 265-271.

LoPiccolo, J. \& Lobitz, W. The role of masturbation the treatment of orgasmic dysfunction. Archives of Sexual Behavior, 1972, 2, 163-171.

LoPiccolo, J. \& Steger, J. The sexual interaction inventory: A new instrument for assessment of sexual dysfunction. Archives of Sexual Behavior, 1974, 3, 585-595.

Mann, J. A comparison of the effects of direct versus vicarious individual and group desensitization of test-anxious students. Unpublished masters thesis. University of Arizona, 1969.

Masters, W. H. \& Johnson, V. E. Human Sexual Response. Boston: Little Brown \& Co., 1966.

Masters, W. H. \& Johnson, V. E. Human Sexual Inadequacy. Boston: Little Brown \& Co., 1970 . 
McBride, A. F. \& Hebb, D. O. Behavior of the captive bottle-nose dolphin, Tursiops truncatus. Journal of Comparative Physiological Psychology, 1948, XII, 111-123.

McCarthy, B., Ryan, M. \& Johnson, F. Sexual Awareness. San Francisco: Scrimshaw Press Inc., 1975.

McCary, J. L. \& Copeland, D. R. (Ed.), Modern Views of Human Sexual Behavior. Chicago: Science Research Associates, Inc., 1976.

McMullen, S. J. Automated procedures for treatment of primary prgasmic dysfunction. Dissertation International, 1977, 37, 10-B, 5364-5365.

McMullen, S. J. \& Rosen, R. Self administered masturbation training in the treatment of primary orgasmic dysfunction. Journal of Consulting and Clinical Psychology, 1979, 47, 912-918.

Malamud, W. \& Palmer, G. The role played by masturbation in the causation of mental disturbances. Journal of Nervous and Mental Disorders, $1932,76, \frac{19220-366}{}$.

Meagher, J. Quackery de luxe: A form of medical charlatanism known as orificial or constructive surgery. New York Medical Journal, 1923, 117, 224-230.

Mikulas, I. Behavior Modification: An Overview. New York: Harper \& Row, 1972 .

Miller, W. \& Lief, H. Masturbatory attitudes, knowledge and experience: Data from the Sex Knowledge and Attitude Test (SKAT). Archives of Sexual Behavior, $1976,5,447-467$.

Moore, W. Some ecomonic functions of genital masturbation during adolescent development. In Marcus \& Francis (Ed.), Masturbation From Infancy to Senescence. New Jersey: Library of Human Behavior, 1975.

More, J. The use of videotape and film in sexual therapy. Paper presented at the 8lst Annual Convention of the American Psychological Association, Montreal, Canada, 1973.

Morrison, E. S. \& Borosage, V. (Ed.), Human Sexuality, Contemporary Perspectives, Second Edition. Michigan: Mayfield Publishing Co., 1973. 
Morrison, E. S. \& Price, M. Values in Sexuality, a New Approach to Sex Education. New York: Hart Publishing Co., Inc., 1974.

Mosher, D. L. Psychological reactions to pornographic films. Technical Reports of the Commission on Obsenity and Pornography, Volume VIII. Washington, D.C.: U. S. Government Printing Office, 1971.

Mosher, D. L. Sex differences, sex experience, sex guilt and explicitly sexual films. Journal of Social Issues, 1973,29 , (3), 95-112.

Mosher, D. I. Negative attitudes toward masturbation in sex therapy Journal of Sex and Marital Therapy, $1979,5,315-3 \overline{33}$.

Neuringer, C. \& Michael, J. (Ed.), Behavior Modification in Clinical Psychology. New York: Appleton-CenturyCrofts, 1970 .

O'Connor, B. D. Modification of social withdrawal through symbolic modeling. Journal of Applied Behavioral Analysis, 1969,2 , 15-22.

Powdermaker, H. Life in Lesu. New York: W. W. Norton \& Co., 1933 .

Pullias, E. V. Masturbation as a mental hygiene problem a study of the beliefs of 75 young men. Journal of Abnormal and Social Psychology, 1937, XXXII, 216 .

Rachman, S. Systematic desensitization. Psychological Bulletin, 1967, 93-103.

Rachman, S. Behavior therapy and psychodynamics. Behavior Therapy, 1970, 1, 527-530.

Rachman, S. Clinical applications of observational learning, imitation and modeling. Behavior Therapy, 1972, 3, 379-397.

Reisinger, J. Generalization of treatment effects following masturbation training with erotic stimuli. Journal of Behavior Therapy \& Experimental Psychiatry, 1979, 10, 247-250.

Renick, J. T. The use of films and videotapes in the treatment of sexual dysfunction. Paper presented at the 81 st Annual Convention of the American Psychological Association, Montreal, Canada, 1973. 
Rilman, P., Wanlass, R., Sabalis, R. \& Sullivan, B. Sex education: A review of its efforts. Archives of Sexual Behavior, 1981, 10, 117-205.

Robinson, C. H. The effects of observational learning on sexual behaviors and attitudes in orgasmic dysfunctional women. Unpublished doctoral dissertation, University of Hawaii, 1974.

Robinson, C. H. The effects of observational learning on the masturbation patterns of preorgasmic females. Paper presented at the annual meeting of the Society for the Scientific Study of Sex, Las Vegas, Nevada, 1974 .

Rush, A. Getting Clear, Body Work for Women. New York: Random House, Inc., 1973.

Sarlin, C. Masturbation, culture and psychosexual development. In Marcus \& Francis (Ed.), Masturbation From Infancy to Senescence. New Jersey: Library of Human Behavior, 1975.

Schaefer, L. Women and Sex. New York: Pantheon Books, 1973.

Schuetz, C. W. Characteristics of masturbators and non masturbators in a female population. Dissertation Abstracts International, $1978,38,10-\bar{A}, 5936-5937$.

Sherfey, M. J. The Nature and Evolution of Female Sexuality. New York: Randon House, 1966.

Skinner, B. F. About Behaviorism. New York: Random House, 1976.

Spitz, R. A. Authority and masturbation: Some remarks on a bibliographical investigation. Psychoanalytic Quarterly, 1952, 21, 490-527.

Stekel, W. Autoeroticism, a Psychiatric Study of Masturbation and Neurosis, translated by Teslaar, J. S. London: 1951 .

Stern, A. Masturbation: It's role in the neurosis. American Journal of Psychiatry, 1929, 9, 1081-1092.

Stone, L. What about the evils of masturbation? Clinical Medicine and Surgery, $1927,34,819-825$. 
Tissot, S. A. Onanism, or a Treatise Upon the Disorders Produced by Masturbation: Or the Dangerous Effects of Secret and Excessive Venery, translated by Hume. London: 1766 .

Wallace, D. H. \& Barbach, L. G. Preorgasmic group treatment. Journal of Sex and Marital Therapy, 1974, 1, $146-154$.

Wilson, S., Strong, B., Clarke, L., \& Thomas, J. Human Sexuality, a Text with Readings. San Francisco: West Publishing Co., 1977.

Wincze, J. P. A comparison of systematic desensitization and "vicarious extinction" in a case of frigidity. Journal of Behavior Therapy and Experimental Psychiatry, 1971, 2, (4), 285-289.

Wincze, J. P. \& Caird, W. K. A comparison of systematic desensitization and video desensitization in the treatment of sexual frigidity. Paper presented at the meeting of the Association for the Advancement of Behavior Therapy, Miami, Florida, 1973.

Wolpe, J. Psychotherapy by Reciprocal Inhibition. Stanford: Stanford University Press, 1958 .

Wolpe, J. Foreward. In C. M. Franks (Ed.), Behavior Therapy: Appraisal and Status. New York: McGrawHill, 1969, ix-xiii.

Wolpe, J. The Practice of Behavior Therapy. New York: Pergamon Press, 1969 .

Wolpe, J. Isolation of a conditioning procedure as the crucial psychotherapeutic factor: A case study. Journal of Nervous and Mental Disorders, 1962, 134, (4), 316-329. 
Advertisement For Research Subjects

Female researcher and research assistant need student. female volunteers, aged 18 or over, for an experiment designed to examine particular attitudes held and behaviors engaged in by females in this culture. The experiment involves no painful stimulation.

For further information, all qualified interested female students are asked to attend a thirty minute briefing at one of the following times at the locations specified below. Only those individuals deciding to participate will be asked to remain for an additional thirty minutes to complete questionnaires. 
APPENDIX B

I N F O R M E D

NOTE :

The videotapes and film to be shown in conjunction with this project were designed to be used for educational purposes only. All audiovisual material to be shown here were selected as an integral part of research currently being conducted for a Masters thesis at Portland State University.

These visual materials include the discussion of topics which are sexually explicit and a film, made at the University of California, San Francisco, which depicts sexually explicit behavior.

Only those persons who are at least 18 years of age may view the film. Those who are offended by discussions about sexual conduct, or those who would be offended by viewing a film depicting sexually explicit behavior are advised not to view the films.

I HAVE BEEN INFORMED AND FULLY UNDERSTAND THAT, AS A PARTICIPANT IN THIS RESEARCH, I MAY BE ASKED TO VIEW

SEXUALLY EXPLICIT TOPICS AND A FILM WHICH DEPICTS SEXUALLY EXPLICIT BEHAVIOR. IN VIEW OF THIS INFORMATION, I HEREBY GIVE MY CONSENT TO VIEW THIS MATERIAL AND ATTEST TO THE FACT THAT I AM AT LEAST 18 YEARS OF AGE.

(Subject in the research) 
APPENDIX C

DEMOGRAPHIC OUESTIONNAIRE

Age

preferred Faith

If none, write NONE

Ethnic Background

(Check one)

Chicano

Chinese

Arab

Korean

Caucasian

Iranian

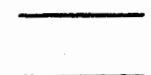

Thai

Black

Japanese

other

\section{Marital Status}

Single and

Never Married

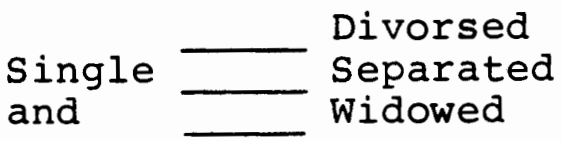
Widowed

\section{Income Level}

If you are independent of a larger family or marital unit, enter your own income. If you are part of a larger income level, indicate the level of the unit in gross amount annually.

$$
\begin{array}{r}
\text { Over } \$ 12,500 \text { annually } \\
10,000-12,499 \\
7,500-9,999 \\
5,000-7,499 \\
2,500-4,999 \\
\text { Under } \$ 2,500 \text { annually }
\end{array}
$$

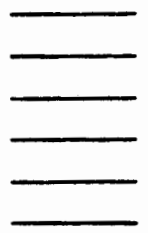

\section{Residential Status}

Currently living

with intimate/mate
Not currently living with intimate/mate

Educational Level

Undergraduate

Graduate

Postbaccalaureate

Religious Devoutness

Please rate yourself on the following scale, measuring devoutness as the constancy of willful attendance of religious fun- 
Appendix c Continued

ctions/services in combination with belief in and adherence to religious doctrine.

$\mathrm{L}_{\text {Devout }}^{\begin{array}{l}\text { Dery } \\ \text { Devout }\end{array}} \begin{aligned} & \begin{array}{l}\text { Moderately } \\ \text { Feminist Sentiment }\end{array} \\ & \text { Devout }\end{aligned}$

Using the following quote as a definition, check the statement which best describes how you would define yourself.

"A feminist is a person who feels a shared commitment to change the sexist institutions and values which limit women's lives." ( as defined in The New Woman Survival Sourcebook )

According to the above definition, I consider myself to be: a feminist undecicled or have mixed feelings not a feminist 
APPENDIX D

\section{PERSONAL SEXUAL INFORMATION SHEET}

1. Those individuals whom I prefer to sexually interact with are:

Members of the same sex (homosexual)
Members of both sexes

(bisesual)
Members of the opposite sex (heterosexual)

2. Currently I would rate my own sex drive and sexual interest as: (Circle the number most closely approximating your response)

$\begin{array}{ccccc}\text { No } & \text { Slight } & \text { Moderate } & \begin{array}{l}\text { More Than } \\ \text { Moderate }\end{array} & \text { High } \\ \text { Sex Drive } & \text { Sex Drive } & \text { Sex Drive } & \text { Sex Drive } & \text { Sex Drive } \\ 1 & 2 & 3 & 4 & 5\end{array}$

3. I am currently involved in a sexual relationship with another person.

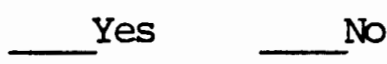

4. I seem to experience a greater amount of sexual tension just prior to my menstral cycle. Yes No

5. I seem to be more sexually active around the time of my menstral cycle than I am during the rest of the month.

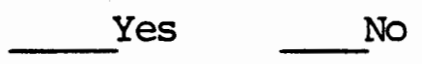

6. Overall, I would say that I am generally satisfied with my own comfort level and my own ability to be sexually responsive.

Yes No

7. Overall, I would say that I am open and joyful in my approach to sexuality.

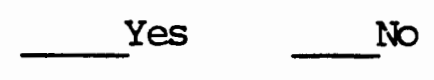

8. Up to this point in your life, have you ever experienced an orgasm through any menas of sexual stimulation?

Yes

No 
APPENDIX E

SEXUAL VARIETY INVENTORY

Ever Engaged

In Behavior ?
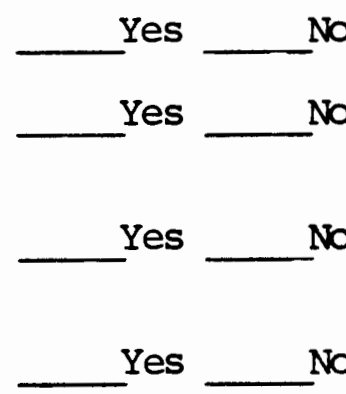

5. Female giving partner a body massage not touching breasts and genitals.

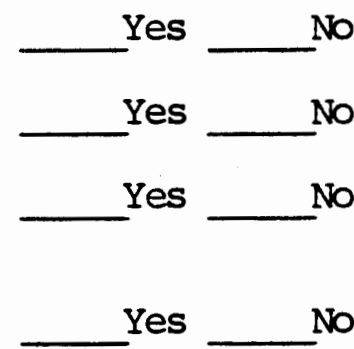

9. Female caressing partner's breasts/chest with mouth.

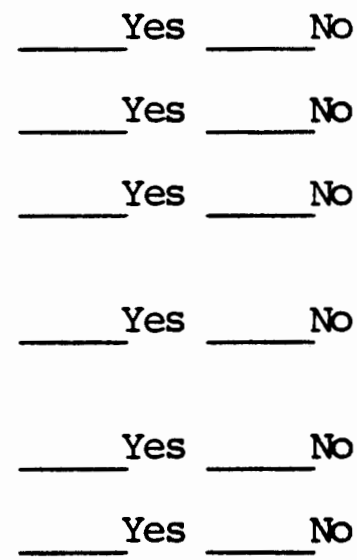

15. Female caressing partner's genitals with hands until partner reaches an orgasm.

10. Female caressing her own genitals

11. Female caressing her own genitals to orgasm.

12. Partner caressing female's genitals with hands.

13. Partner caressing female's genitals with hands until she reaches orgasm.

14. Female caressing partner's genitals with hands. Yes No

Yes No 
16. Partner caressing the female's genitals with mouth.

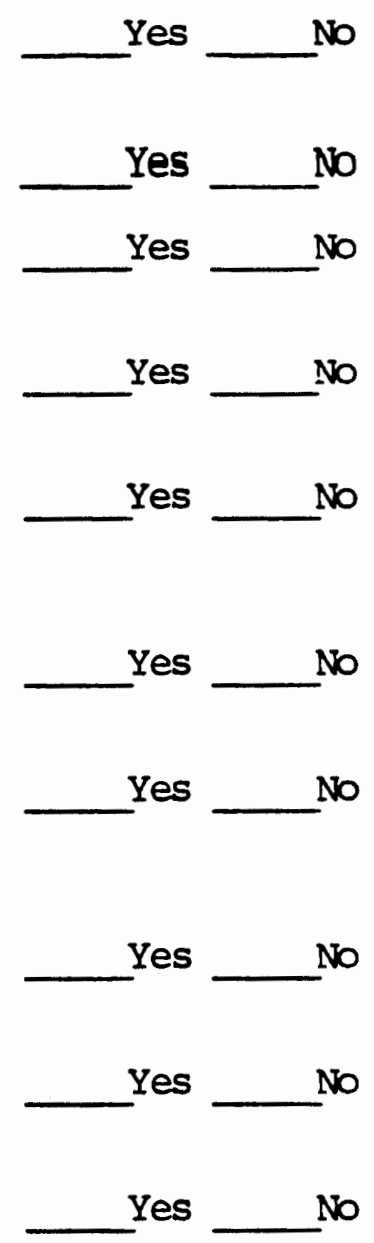

17. Partner caressing female's genitals with mouth until female reaches an orgasm.

18. Female caressing partner's genitals with mouth.

19. Female caressing partner's genitals with mouth until partner reaches an orgasm.

20. Female and partner simultaneously stimulating each others genitals with mouth.

21. Female and partner simultaneously stimulating each others genitals with mouth until each reaches an orgasm.

22. Partner and female simultaneously stimulating each others genitals with hands.

23. Partner and female simultaneously stimulating each others genitals with hands until each reaches an orgasm.

24. Female and partner having sexual intercourse (penile/vaginal penetration).

25. Female and partner having sexual intercourse with both of them having an orgasm. 


\section{APPENDIX F}

ATTITUDES TOWARD MASTURBATION QUESTIONNAIRE ${ }^{1}$

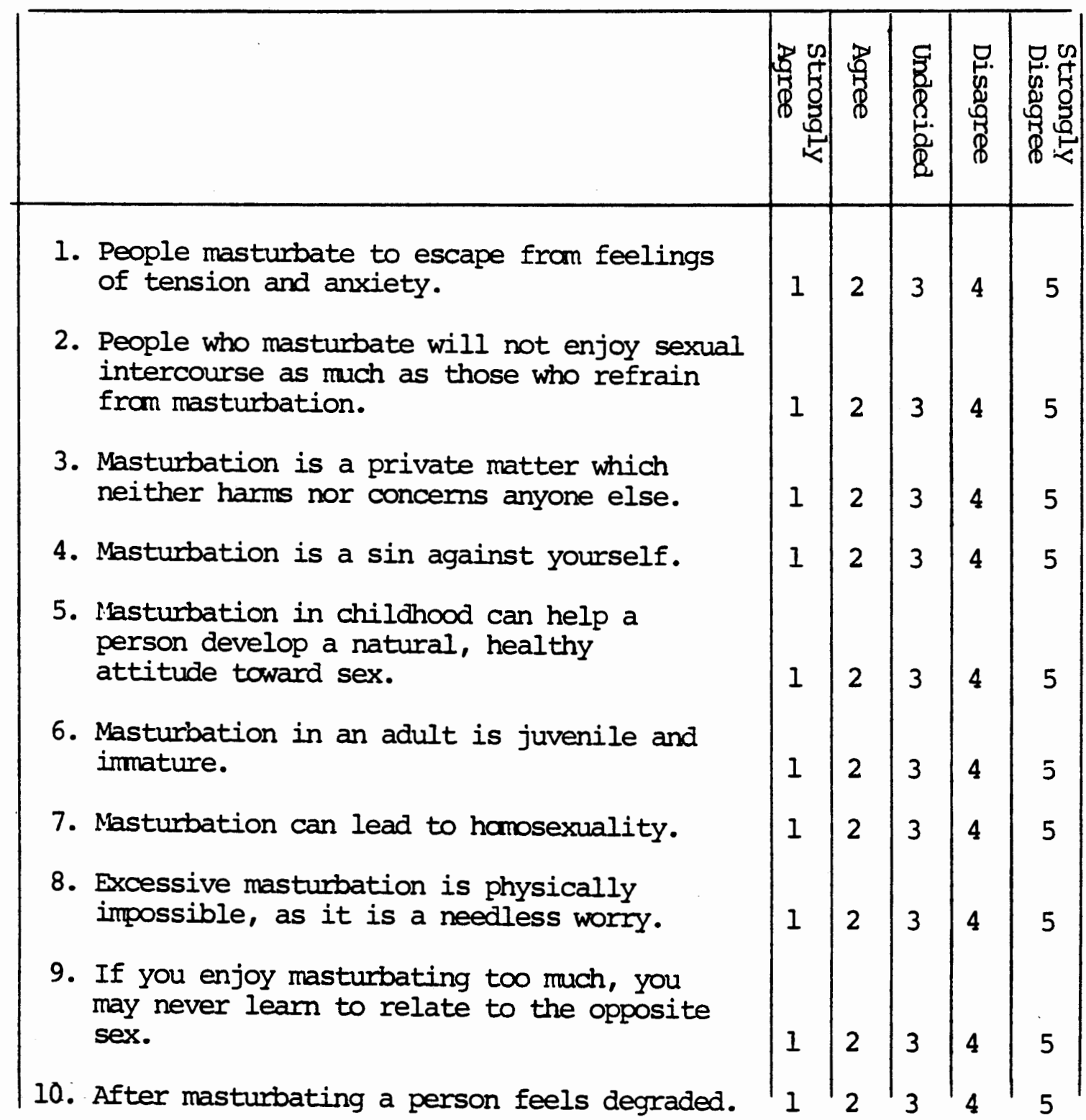

'Paul R. Abramson and Donald L. Mosher, The Development of a Measure of Negative Attitudes Toward Masturbation. Journal of Consulting and Clinical Psychology, 1975, 43(4), 485-490. 
APPENDIX F (continued)

\begin{tabular}{|c|c|c|c|c|c|}
\hline & 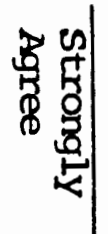 & 蒙 & $\begin{array}{l}\text { S. } \\
\frac{8}{8} \\
\frac{8}{3} . \\
\frac{8}{8}\end{array}$ & 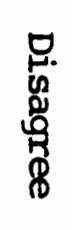 & 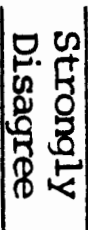 \\
\hline $\begin{array}{l}\text { 11. Experience with masturbation can potentially } \\
\text { help a woman become orgastic in sexual } \\
\text { intercourse. }\end{array}$ & 1 & 2 & 3 & 4 & 5 \\
\hline 12. I feel guilty about masturbating. & 1 & 2 & 3 & 4 & 5 \\
\hline $\begin{array}{l}\text { 13. Masturbation can be a "friend in need" } \\
\text { when there is no "friend in deed". }\end{array}$ & 1 & 2 & 3 & 4 & 5 \\
\hline $\begin{array}{l}\text { 14. Masturbation can provide an outlet for } \\
\text { sex fantacies without haming anyone } \\
\text { else or endangering oneself. }\end{array}$ & 1 & 2 & 3 & 4 & 5 \\
\hline $\begin{array}{l}\text { 15. Excessive masturbation can lead to problems } \\
\text { of impotence in men and frigidity in } \\
\text { women. }\end{array}$ & 1 & 2 & 3 & 4 & 5 \\
\hline $\begin{array}{l}\text { 16. Masturbation is an escape mechanism } \\
\text { which prevents a person from developing } \\
\text { a mature sex outlook }\end{array}$ & 1 & 2 & 3 & 4 & 5 \\
\hline $\begin{array}{l}\text { 17. Masturbation can provide hamless relief } \\
\text { from sexual tensions. }\end{array}$ & 1 & 2 & 3 & 4 & 5 \\
\hline $\begin{array}{l}\text { 18. Playing with your own genitals is } \\
\text { disgusting. }\end{array}$ & 1 & 2 & 3 & 4 & 5 \\
\hline $\begin{array}{l}\text { 19. Excessive masturbation is associated with } \\
\text { neurosis, depression and behavioral } \\
\text { problems. }\end{array}$ & 1 & 2 & 3 & 4 & 5 \\
\hline 20. Any masturbation is too much. & 1 & 2 & 3 & 4 & 5 \\
\hline $\begin{array}{l}\text { 21. Masturbation is a compulsive, addictive } \\
\text { habit which once begun is almost } \\
\text { impossible to stop. }\end{array}$ & 1 & 2 & 3 & 4 & 5 \\
\hline 22. Masturbation is fun. & 1 & 2 & 3 & 4 & 5 \\
\hline $\begin{array}{l}\text { 23. When I masturbate, I am disgusted with } \\
\text { myself. }\end{array}$ & 1 & 2 & 3 & 4 & 5 \\
\hline
\end{tabular}


APPENDIX F (Continued)

\begin{tabular}{|c|c|c|c|c|c|}
\hline & 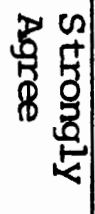 & 葶 & 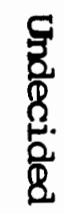 & 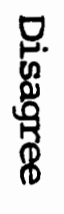 & 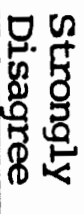 \\
\hline $\begin{array}{l}\text { 24. A pattern of frequent masturbation is } \\
\text { associated with introversion and } \\
\text { withdrawal from social contacts. }\end{array}$ & 1 & 2 & 3 & 4 & 5 \\
\hline $\begin{array}{l}\text { 25. I would be ashamed to admit publicly } \\
\text { that I have masturbated. }\end{array}$ & 1 & 2 & 3 & 4 & 5 \\
\hline $\begin{array}{l}\text { 26. Excessive masturoation leads to mental } \\
\text { dullness and fatique. }\end{array}$ & 1 & 2 & 3 & 4 & 5 \\
\hline 27. Masturbation is a normal sexual outlet. & 1 & 2 & 3 & 4 & 5 \\
\hline $\begin{array}{l}\text { 28. Masturbation is caused by an excessive } \\
\text { preoccupation with thoughts about sex. }\end{array}$ & 1 & 2 & 3 & 4 & 5 \\
\hline $\begin{array}{l}\text { 29. Masturbation can teach you to enjoy the } \\
\text { sensuousness of your own body. }\end{array}$ & 1 & 2 & 3 & 4 & .5 \\
\hline $\begin{array}{l}\text { 30. After I masturbate, I am disgusted with } \\
\text { myself for losing control of my body. }\end{array}$ & 1 & 2 & 3 & 4 & 5 \\
\hline
\end{tabular}




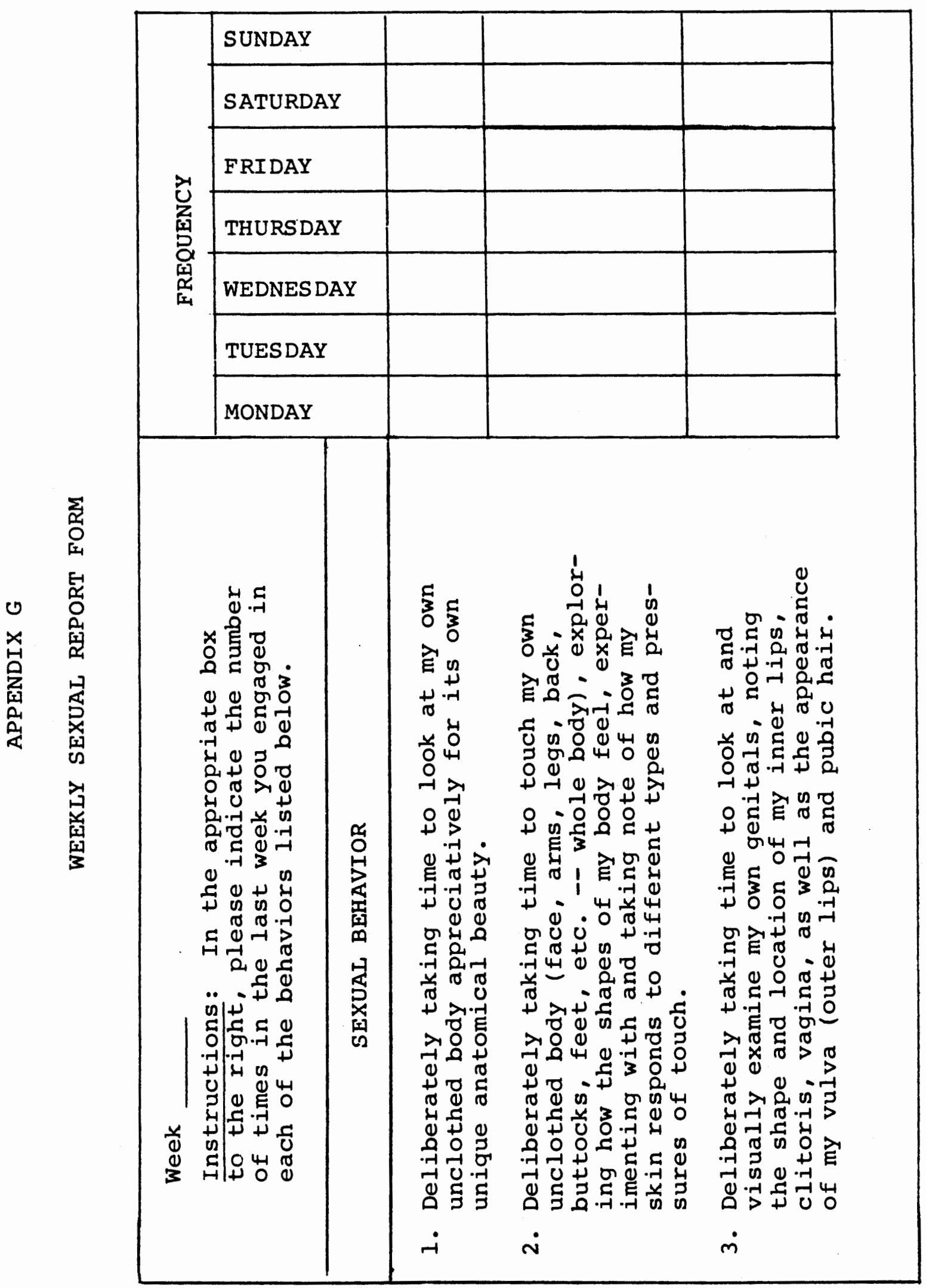




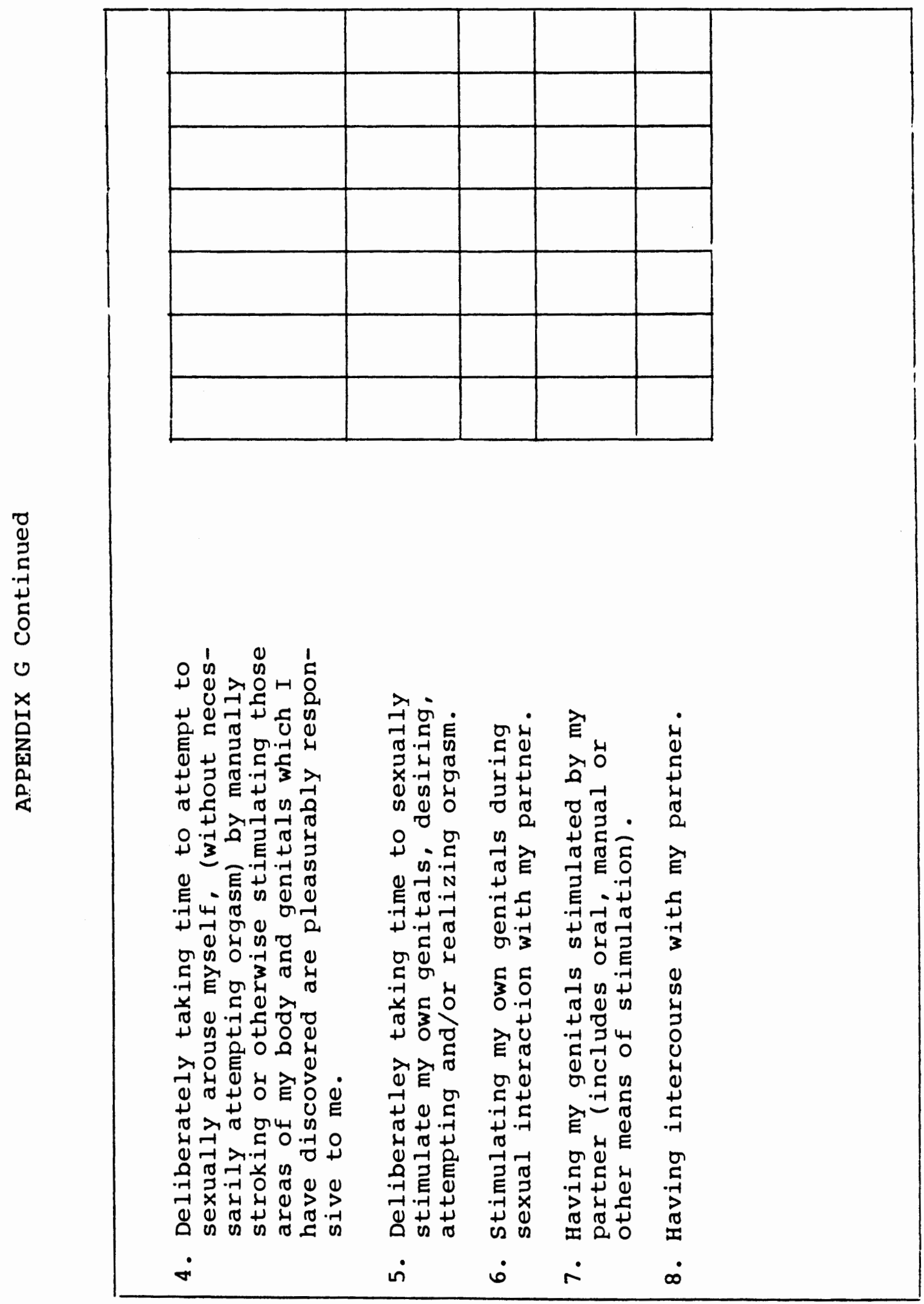




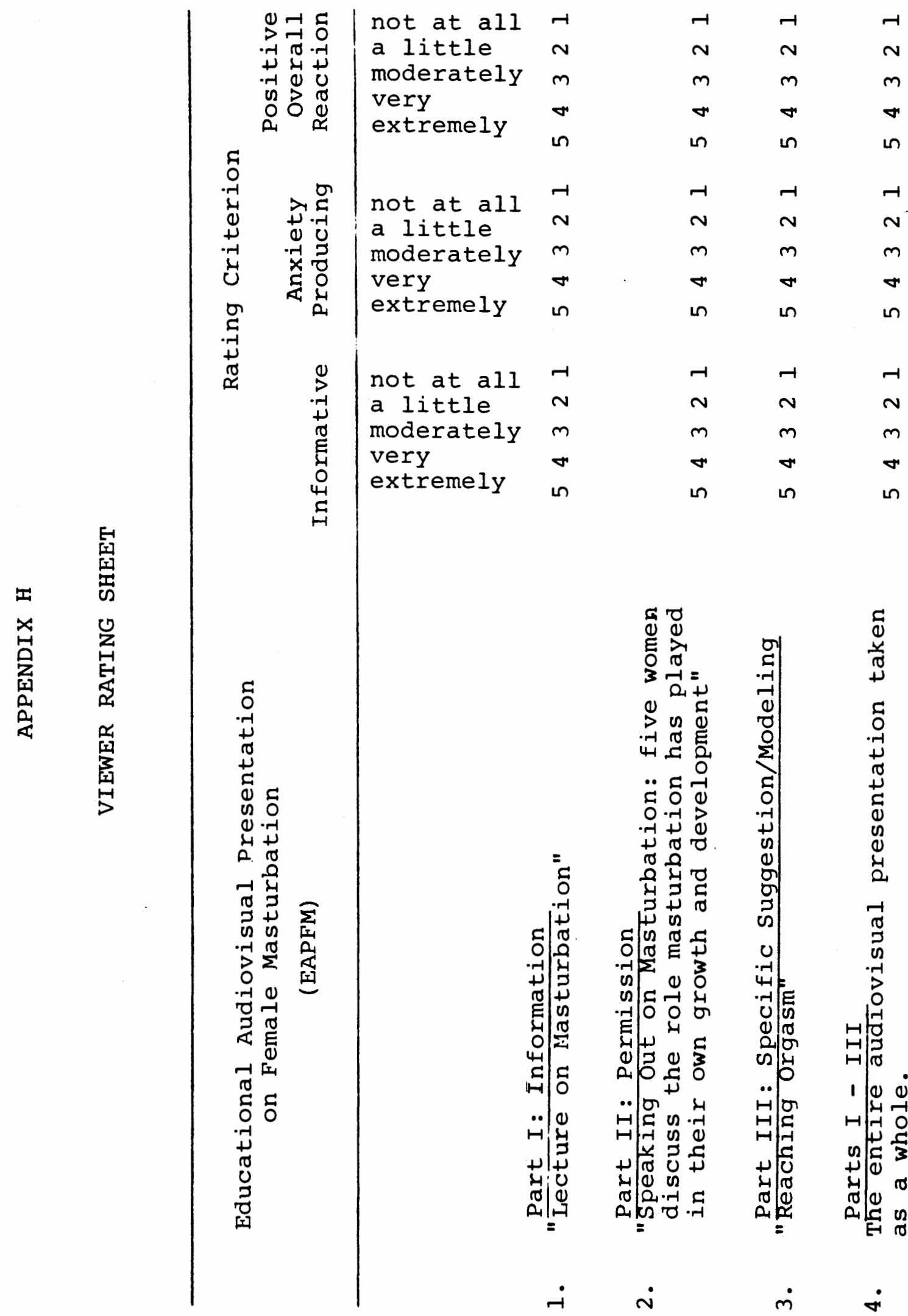


FOLLOW UP QUESTIONNAIRE

1. Do you feel that the experimenter had a point to prove? Yes No

If yes, in your opinion, what was the point of the experiment? Please list below.

2. Do you feel that you had an accurate perception of the design and purpose of the current study?

Yes

If yes, do you feel that your knowledge biased the objectivity of your responses?

Yes No

3. Do you feel that having to record your sexual behavior influenced the frequency of engaging in those behaviors?

Yes No

If yes, do you feel that it tended to:

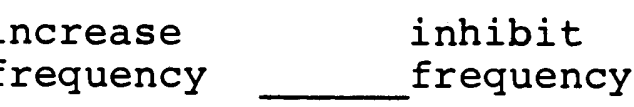

4. Do you feel that participating in this study had any kind of unanticipated undesirable impact on:

1. You personally?

2. You and a sexual partner?

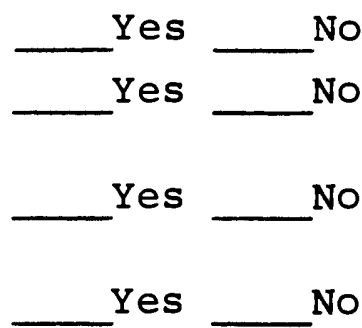

3. Your routine sexual behavior or attitudes?

4. Your attitudes toward or masturbatory behavior?

Yes

No

Please elaborate in the space provided on those items answered "yes" or others on which the study had a similar effect. 


\section{APPENDIX I (Continued)}

5. Do you feel that participating in this study had a positive or desirable impact on:

1. You personally?

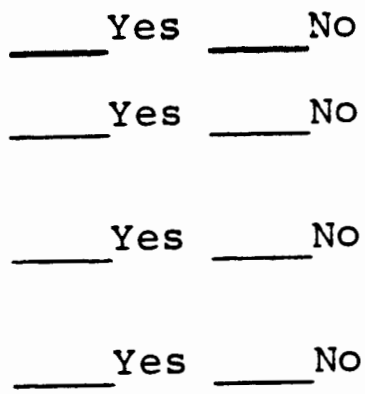

4. Your attitudes toward or masturbatory behavior?

partner?

3. Your routine sexual behavior or attitudes? No

Please elaborate in the space provided on those items answered "yes" or other on which the study had a similar effect. 